\title{
O "PESSIMISMO SENTIMENTAL" E A EXPERIÊNCIA ETNOGRÁFICA: POR QUE A CULTURA NÃO É UM “OBJETO" EM VIA DE EXTINÇÃO (PARTE II)
}

Marshall Sahlins

\section{Epeli Hau'ofa: a sociedade transcultural}

N ascido na N ova Guiné, filho de pais tonganeses; educado na PapuaN ova Guiné, Tonga, Fiji, Canadá e Austrália; ex-secretário particular adjunto [Deputy Private Secretary] do rei de Tonga, e atualmente professor-titular e diretor da School of Social and Economic Development da Universidade do Pacífico Sul em Suva, Fiji; doutor em antropologia pela Universidade Nacional da Austrália, com uma tese baseada em seu trabal ho de campo junto aos M ekeo de Papua; autor de notáveis obras de ficção, assim como de monografias especializadas sobre a sociedade mekeo e sobre o desenvolvimento econômico em Tonga, Epeli Hau'ofa encarna, em sua própria biografia, a visão daquele espaço de vida oceânico criado pelo livre movimento dos povos insulares, que ele mesmo articulou em 1993, em desafio às concepções neocolonialistas que viam as sociedades do Pacífico como condenadas ao subdesenvolvimento devido ao seu isolamento e às suas múltiplas carências: carência de terra, de população, de recursos e, mais que tudo, de capacidade de empreendimento.

Como professor de uma universidade que atende a doze países insulares do Pacífico, $\mathrm{H}$ au'ofa declarou não poder mais continuar vendendo a seus estudantes esse discurso depreciativo europeu. A ocasião de tal pronunciamento foi uma conferência pública, "N osso mar de ilhas”, proferida durante as celebrações do 25o aniversário da Universidade do Pacífico Sul1. A conferência gerou ondas de choque que se propagaram através do campus, e seu resultado imediato foi um pequeno volume - $\mathrm{A} \mathrm{N}$ ew Oceania: Rediscovering Our Sea of I slands (Waddell, Naidu e Hau'ofa 1993) - contendo a conferência de Hau'ofa e as reações de dezenove colegas. Alguns destes se declararam surpresos com o "idealismo romântico" de Hau'ofa. Com efeito, ele desenvolvia argumentos acerca da auto- 
nomia cultural das pessoas comuns, chegando mesmo a fazer alusões prático-mitológicas que remetiam a atual liberdade de movimento dos povos às viagens lendárias de heróis ancestrais aos mundos celestes e subterrâneos, ao mesmo tempo que parecia ignorar as realidades mundanas - 0 sistema de dominação neocolonial implantado pelas classes dominantes mercantis e pelas corporações multinacionais. Entretanto, em uma reflexão final sobre as críticas recebidas, $\mathrm{H}$ au' ofa chamou a atenção para a consciência cultural do próprio povo, isto é, para um uso auto-reflexivo da "cultura" semel hante ao que então despontava, como veremos, em todo o mundo. Ele lamentava que os intelectuais locais insistissem em ignorar suas tradições culturais em favor das linguagens aparentemente universais da economia e da ciência políticas. Os acadêmicos indígenas estavam falando uma língua estrangeira, enquanto as pessoas comuns se esforçavam em adaptar seus discursos ancestrais à sua situação corrente:

“Lamentavelmente, parecemos ter ignorado a tal ponto a importância de nossas culturas que, sempre que algum de nós busca inspiração e rumo em sua própria herança, nas conquistas de seus ancestrais, acaba atraindo sobre si acusações, provenientes de seu próprio povo, de romantismo, mitificação, especiosidade, emissão de juízos de valor [...]. Ficamos arrepiados quando se menciona nossa cultura, porque associamos nossas tradições ao atraso e à ignorância. Afinal, somos indivíduos internacionalistas e progressistas, que só falamos e pensamos na linguagem universal e acultural da economia e da ciência políticas [...]. A o excluir deliberadamente de qualquer discurso sério nossas tradições em transformação, especialmente aqui na School of Social and Economic Development [da UPS], não levamos em conta o fato de que a maior parte das pessoas ainda as usam e as adaptam como instrumentos de sobrevivência [...]. Creio que devemos prestar muito mais atenção e assumir um compromisso muito mais sólido com nossas culturas do que temos feito até o presente, pois do contrário corremos o risco de nos tornar semelhantes aos tristes mímicos descritos por V. S. Naipaul" (Waddell, Naidu e Hau'ofa 1993:129).

A própria réplica de Hau'ofa, desse modo, recorria a fontes culturais tradicionais, pois, como mostram muitos de seus trabalhos, ele conhece bem aquele ceticismo que acompanha os sistemas de autoridade polinésios, aquela sutil disposição popular para a subversão que serve de complemento tradicional às contradições estruturais na esfera do parentesco e do poder político. Recorrendo a esse mesmo espírito popular, Hau'ofa sabotava as teorias estrangeiras e imperialistas sobre a "dependência" e 
a "modernização", segundo as quais as sociedades insulares seriam pobres demais para atingir qualquer coisa de vagamente semelhante a um "desenvolvimento" autônomo, ou mesmo para conquistar algum respeito próprio. É assim que seriam as "sociedades MIRAB"* — este o nome infeliz por que eram conhecidas na Universidade do Pacífico Sul-, subsistindo à custa de migrações, de remessas de dinheiro dos emigrantes, de ajuda externa e de uma burocracia inchada. A noção de sociedades MIRAB, proposta pela primeira vez por Bertram e Watters (1986), teve, sem dúvida, o mérito histórico de situar as ilhas do Pacífico em um sistema de relações internacionais, senão mesmo de as conceber como abrigando sociedades verdadeiramente internacionais. O problema, entretanto, era o papel cultural puramente reativo que o conceito de MIRAB atribuía aos povos insulares. "As forças decisivas [...] procederam do exterior, mais que de qualquer dinâmica interna; [os povos nativos] responderam sempre por reacomodações locais" (Watters 1987:35-37). Tratava-se de um "processo gerado externamente", que "dominou de maneira crescente e decisiva as respectivas sociedades insulares, determinando em larga medida sua evolução" (Bertram e Watters 1986:55, 47). Nada de bom podia resultar de tal dependência para países "extremamente pequenos, pobres em recursos, isolados, com economias geralmente monocultoras, mercados internos limitados, custos de transporte muito elevados, balanças comerciais desequilibradas e vários outros problemas muito peculiares" (Watters 1987:42)2. Durante os anos 80, Hau'ofa havia sido um cúmplice relutante dessa ideologia do desespero. Em 1986, ele escreveu, no contexto de um seminário sobre "desenvolvimento", um trabalho acerca das sociedades do Pacífico intitulado "Sobre as Implicações de se Ser Muito Pequeno", que era um verdadeiro catálogo das lamentações econômicas suscitadas por essa condição pouco interessante. Além do mais, argumentava Hau'ofa, a situação geográfica das ilhas, combinada com suas proporções liliputianas, fazia com que sua soberania fosse tão vulnerável às maquinações das potências presentes no Pacífico quanto o eram suas ecologias aos testes nucleares "e a outras coisas que os países grandes não ousam fazer em casa". O pequeno pode ser bonito para algumas pessoas, disse Hau'ofa, "mas o resto do mundo transformou nosso tamanho diminuto e nossa localização geográfica na causa de nossa miséria".

\footnotetext{
* N. T. - MIRAB é um acrônimo formado a partir de "migration", "remittance", "aid" e "bureaucracy".
} 
Ainda assim, nesse e em alguns outros trabalhos, havia sempre uma certa ambivalência no pessimismo de Hau'ofa. A té mesmo o relatório sobre comercialização por ele compilado para o governo tonganês estava sal picado de descrições levemente irônicas, mostrando como as inclinações habituais das pessoas conseguem solapar os mais variados esquemas de desenvolvimento de inspiração estrangeira (Hau'ofa 1979:4-5, 8, 119). De maneira análoga, no texto "Sobre as Implicações de se Ser M uito Pequeno", Hau'ofa percebia o assim chamado desenvolvimento urbanização, expansão do setor monetário etc. - como uma ameaça de empobrecimento pesando sobre a tradicional "abundância de meios de subsistência" [subsistence affluence] característica das ilhas. Em certas passagens do trabalho, a trágica condição de pequenez e insuficiência era analisada como uma "armação" ideológica de origem estrangeira, vendida aos povos insulares por autodesignados especialistas em desenvolvimento econômico:

“[...] em qualquer publicação sobre ajuda externa e desenvolvimento na região, vocês provavelmente lerão que somos sociedades minúsculas, dispersas, pobres em recursos e incapazes de ficar de pé sozinhas no mundo moderno. Essa idéia tem sido inculcada em nós de modo tão consistente que nosso povo e nossos próprios líderes estão convencidos de nossa insignificância e, portanto, de nossa impotência" (1986:7).

Foi, porém, em sua obra de ficção, especialmente em Tales of the Tikongs (1983), que o ressentimento populista de Hau'ofa se exprimiu em sua forma mais forte e mais polinésia. Eu disse "populista", mas o que há de polinésio nesse hilariante adeus ao "desenvolvimento" é precisamente o fato de que as pessoas comuns não falam a partir de uma posição de dependência de classe; ao contrário, elas se vêem como o verdadeiro povo da terra, em contraste com os chefes governantes e em oposição a eles, que fazem remontar suas origens aos céus e a outros lugares estrangeiros. Assim, os inúteis burocratas da diminuta ilha fictícia de Tiko estão sempre indo a conferências em Wellington, seminários em Genebra e cursos de treinamento em Londres, enquanto os conselheiros técnicos estrangeiros enviados a Tiko pela Grande Organização Internacional se mostram completamente perdidos diante dos conhecimentos e subterfúgios nativos 3 . Em "Our Sea of Islands", ele fala de

“[...] pessoas comuns, camponeses e proletários, que, devido ao fluxo insuficiente de benefícios vindos de cima, ao ceticismo diante das políticas públi- 
cas oficiais e a outras razões semelhantes, tendem a planejar e a tomar decisões sobre suas vidas de maneira independente, por vezes com resultados surpreendentes e dramáticos, que passam despercebidos ou são ignorados nas esferas superiores da sociedade. A lém disso, os especialistas acadêmicos e consultores econômicos tendem a desvalorizar ou a interpretar erroneamente as práticas locais, porque estas não se enquadram nas visões dominantes sobre a natureza da sociedade e de seu desenvolvimento. Dessa forma, as visões acerca do Pacífico tomadas da perspectiva da macroeconomia e da macropolítica freqüentemente diferem de modo notável da visão das pessoas comuns" (1993:2-3).

Não é preciso acreditar, portanto, que a conversão de Hau'ofa a uma posição desafiadora diante do tema do infortúnio insular tenha sido tão dramática quanto ele alega. Digo "conversão" porque, em "Our Sea of Islands", Hau' ofa descreve uma viagem que fez, em 1993, entre Hilo e Kona, na ilha principal do arquipélago havaiano, como tendo sido seu "caminho de Damasco". Surgindo das profundezas infernais e se derramando até o mar, a lava do vulcão Kilaeua, sob a égide da deusa Pele, parecia-Ihe uma metáfora mais adequada do cosmos nativo que as fronteiras políticas e as "reservas mentais" às quais as determinações ocidentais tinham confinado a existência das sociedades insulares há tanto tempo. Não vivemos hoje, e não vivemos nunca, disse ele, aprisionados em nossas "ilhotas perdidas em um mar distante", como quer parecer aos europeus. O mar é nosso lar, como o era para nossos ancestrais. O mundo dos ancestrais "era tudo menos acanhado. Eles pensavam e narravam seus próprios feitos em termos épicos" (1993:7). Eles viviam em grandes associações de ilhas ligadas pelo mar - como no anel do kula, ou na comunidade regional de Tonga, Fiji, Uvea, Samoa, Rotuma, Futuna e Tokelau —; ligadas, note-se bem, e não separadas pelo mar.

A pós a Segunda Guerra, continua Hau'ofa, os povos do Pacífico conseguiram retomar seu controle tradicional do espaço oceânico, ainda que por novos meios, com novos objetivos e em toda uma outra escala. Eles agora expandem suas ilhas sob formas novas:

“Em todo lugar aonde vão, Austrália, Nova Zelândia, Havaí, Estados Unidos continental, Canadá e mesmo Europa, eles deitam raízes em novas áreas de recursos, obtendo emprego e estabelecendo propriedades familiares no ultramar, expandindo as redes de parentesco através das quais fazem circuIar a si mesmos, a seus parentes e a suas histórias através do oceano; o oceano Ihes pertence, porque sempre foi seu lar" (1993:10). 
Em contraste com as concepções ocidentais sobre sua pequenez, os ilhéus do Pacífico embarcaram em um processo inédito de "ampliação do mundo". Em lugar de recursos fixos e insuficientes, eles ganharam acesso aos produtos de uma divisão de trabalho internacional, pois seus "lares alhures", na expressão de Hau' ofa, estão unidos por laços de parentesco e por um intercâmbio de pessoal - sem esquecer as comunicações por telefone, fax e correio el etrônico - à ilha natal, que ainda é a base de sua identidade e seu destino. Tampouco é preciso recorrer ao economês ocidental e falar em remittances [remessas de dinheiro dos migrantes]. As trocas são bilaterais, são algo semelhante à reciprocidade costumeira entre parentes, mostrando aspectos de um sistema de prestações totais que acrescenta valores sociais determinados às transações ${ }^{4}$. Hau'ofa nos fala do fluxo de objetos e alimentos que seguem de Tonga para Auckland e Honolulu, e do fluxo contrário de dinheiro e de objetos como geladeiras e motores de popa. Entretanto, aquilo que aparece como "remessas" e "pagamentos" é apenas a dimensão material de uma circulação de pessoas, direitos e cuidados entre as ilhas natais e os lares alhures. As fronteiras internacionais e as distâncias oceânicas que, na concepção ocidental do espaço planetário, significam diferença e isolamento, são atravessadas por um sistema especificamente tonganês de relações sociais e culturais. Os ilhéus de Tonga - bem como os de Samoa, Tuvala ou das ilhas Cook - vivem em comunidades multilocais de dimensões globais. Eles expandiram seu horizonte e potencialidades culturais de um modo que escapa totalmente à compreensão daquelas teorias economicistas e desenvolvimentistas que postulavam sua insignificância. E afinal de contas, que povo haveria de se conceber a si mesmo como "remoto"?

George M arcus (1981:59) apresentou alguns exemplos bastante ilustrativos das redes oceânicas do parentesco tonganês. Tais parentelas são tipicamente encabeçadas por um personagem da antiga aristocracia ou por um membro da nova elite plebéia, normalmente residente na ilha principal de Tonga. A seção local, tonganesa, de uma das redes da elite plebéia descrita por M arcus inclui um burocrata de alto escalão, três funcionários públicos de nível médio, um executivo da estação de rádio local, um portador de título de doutor devidamente empregado, e três professores. Esse grupo tinha direitos hereditários sobre três áreas de cultivo, além de arrendar outras cinco, e tinha uma participação considerável em empreendimentos de agricultura comercial. Possuía ainda dois terrenos urbanos e duas lojas de varejo. Os membros da parentela estabelecidos no Havaí estavam no ramo dos manufaturados, vivendo, além disso, da renda proveniente do aluguel de imóveis. Três dessas pessoas estuda- 
vam na universidade. Dentre os parentes vivendo na Califórnia, por sua vez, havia o proprietário e operador de um posto de gasolina e dois empregados do aeroporto de São Francisco; este ramo tinha duas propriedades residenciais. Em Utah, três membros da parentela estavam empregados como trabalhadores não qualificados; um outro era professor. Na N ova Zelândia, havia um parente trabalhando no setor de transportes, dois estavam na escola secundária e um na universidade. O ramo neozelandês possuía uma propriedade para fins de aluguel e outra para fins residenciais.

Contas feitas, M arcus especulou que, no início dos anos 80, cerca de 30 mil tonganeses estariam morando permanentemente no exterior, para uma população doméstica de 100 mil. A maior concentração de tonganeses além-mar estava na Nova Zelândia (especialmente em Auckland), Austrália, Fiji e Estados Unidos (sobretudo no Havaí, Califórnia e Utah). M as as informações sobre a diáspora tonganesa não são tão acessíveis quanto os materiais referentes a seus vizinhos samoanos; assim, seria interessante tomar este último caso para fins de ilustração e de comparação intercultural.

Em seu livro, pertinentemente intitulado The Samoans: A Global Family (1989), Sutter oferece-nos um relato fascinante sobre a diáspora samoana, através de fotografias e textos, incluindo breves autobiografias de várias das pessoas apresentadas. N ote-se que, em meados da década de 80, aproximadamente um terço da população de Samoa Ocidental estava vivendo no ultramar; enquanto mais de $60 \%$ da população da Samoa americana havia emigrado para o Havaí e os Estados Unidos continental. Os samoanos ocidentais estavam concentrados em Auckland e Wellington, Honolulu, Los Angeles, San Diego e na região da baía de São Francisco; mas viviam também em cidades americanas menores, como Oxnard, na Califórnia, e estavam presentes em cidades tão a leste como Nova Iorque e Chapel Hill. No total, havia samoanos em aproximadamente vinte estados americanos e trinta nações espalhadas pelo mundo.

Em uma das autobiografias dessa diáspora reunidas por Sutter, um detetive em Wellington escreve: "considero-me um samoano legítimo e tenho muito orgulho disso [...]. Consigo visitar minha casa em Samoa a cada dois anos. No momento, estou dando cursos sobre a língua e a cultura samoana no Royal N ew Zealand Police College" (M isiotele in Sutter 1989:167) $)^{5}$.

Um operário de Paremata (Nova Zelândia) justifica sua fuga da comunidade samoana de Tokoroa (N.Z.), dizendo que ali " havia costumes samoanos demais"; mais tarde, ele acabou se reconciliando com a 
família (Alo'iai in Sutter 1989:168). Konishiki, primeiro estrangeiro a ganhar o título de campeão de sumô no J apão, narra as dificuldades que teve com a mídia para ver reconhecida sua identidade: "durante um bom tempo, insistiram em me chamar de havaiano. M as isso finalmente está mudando. Agora informam que sou um samoano nascido no Havaí, o que me dá muito orgulho" (Alo'iai in Sutter 1989:173).

Diversos jogadores profissionais de futebol americano aparecem no texto de Sutter, como, por exemplo, Mosi Tatapu, dos New England Patriots, que se declara "abençoado" por ser samoano, e que dedicou sua participação no Super Bowl de 1985 a seu sogro (Sutter 1989:194). A saga dos samoanos contada por Sutter inclui ainda: um pastor de ovelhas em Invercall (N ova Zelândia); um suboficial da M arinha americana servindo nas Filipinas; um pastor protestante em Zâmbia; uma freira em Roma; um funcionário da UNESCO em Paris, a quem Deus concedeu "a graça de ter nascido samoano, em corpo, mente e alma"; um mestre-cervejeiro em M unique; um engenheiro na N oruega; um clérigo na J amaica; um agente do F.B.I. na Flórida; um operário especializado na construção de arranha-céus em Atlanta; um diretor de atores em Hollywood; um bombeiro no Colorado, que acredita que "os samoanos são capazes de viver em qualquer sociedade e de contribuir para ela", e que tem "orgulho de ser quem sou: um samoano"; e um estudante de doutorado em teologia em Montpellier, na França, que não esquece o aiga (grupo bilateral de parentesco): “espero que o fato de eu escrever na primeira pessoa não venha a obscurecer o apoio coletivo que recebi de minha família, minha esposa e sua família, dos amigos e das pessoas da aldeia. Os caminhos de minha vida foram traçados sobre uma ampla base de apoio comunitário: Samoa" (Sutter 1989:181).

Não se trata aqui apenas de saudade. Enquanto indivíduos, famílias e comunidades de ultramar, os emigrantes são parte de uma sociedade transcultural dispersa, mas centrada na terra natal e unida por uma contínua circulação de pessoas, idéias, objetos e dinheiro. Deslocando-se entre pólos culturais estrangeiros e indígenas, adaptando-se àqueles enquanto mantêm seu compromisso com estes, os tonganeses, samoanos e diversos outros povos como eles têm sido capazes de criar as novas formações que estamos chamando aqui de sociedades transculturais. "De vários modos", nota Craig J anes (1990:58), um etnógrafo dos samoanos moradores da Califórnia setentrional, "Samoa e São Francisco constituem um único campo social marcado por uma substancial circulação de membros". Além disso, sob vários aspectos, "os imigrantes samoanos consideram-se mais samoanos que os samoanos de Samoa" (J anes 1990:62). 
J anes descreve o aiga ou rede de família extensa de São Francisco como tomando uma forma funcional particular, adaptada às exigências da diáspora. $\mathrm{O}$ aiga de ultramar caracteriza-se pela solidariedade dos parentes próximos de mesma geração - em contraste com as hierarquias intergeracionais da terra natal - e por uma interação formal com os parentes distantes mais freqüente que a costumeira em Samoa. A aldeia samoana também se reproduz de modo adaptativo, a saber, como congregação de uma igreja de ultramar. De fato, como observou Macpherson acerca de comunidades samoanas similares na Nova Zelândia: "a alguém que havia trabalhado em Samoa, parecia que os samoanos haviam recriado Samoa na Nova Zelândia, e que tudo acontecia de modo muito parecido com o que acontecia em Samoa" (M acpherson 1978; cf. Kotchek 1978).

A bre-se aqui todo um novo campo para a comparação antropológica: comparação não apenas entre as configurações doméstica e ultramarina das comunidades de uma mesma sociedade translocal, mas também entre diferentes tipos de formações culturais translocais, como a samoana e a tonganesa. George Marcus (1993) chama a atenção para os contrastes entre as coletividades samoanas de ultramar com seus membros fortemente ligados às aldeias de origem em Samoa e as redes de parentela tonganesas, espal hadas por diferentes localidades ultramarinas e ligadas mais a pessoas que a lugares em Tonga - nos casos mais bem-sucedidos, ligadas à elite de nobres e plebeus reunida em torno da capital real de Nuku'al ofa. M arcus sugere que a diferença "poderia ter algo a ver com a extensão no estrangeiro de tipos fundamentalmente diferentes de organização local na terra natal, em Tonga e Samoa" (1993:28). De fato, segundo a sua descrição, o princípio tonganês distintivo é a focalização hierárquica do sistema de parentesco em um personagem da elite - o qual, por sua vez, se orienta e situa em função da realeza -, e é isso que dá definição e coerência ao grupo como um todo. O mesmo princípio hierárquico permite que os recursos dispersos e diversificados da rede sejam consolidados na sede doméstica da elite. Quando M arcus, além disso, sugere que as redes de parentesco no estrangeiro tendem a se romper se não são capazes de converter seus recursos em posições de elite em casa, torna-se clara a continuidade das linhagens da antiga Tonga, elas também dispersas mas centradas nos chefes. Comparemos o que diz Marcus com as observações de Gifford acerca da haa (linhagem) tradicional, usualmente distribuída ao longo do arquipélago, mas sempre com "um chefe como núcleo": "tudo aponta para a necessidade de haver uma linha de chefes poderosos formando um núcleo em torno do qual a linhagem se agrupe. Sem esses chefes, a linhagem parece murchar e morrer, e seus membros 
gradual mente se afiliam a outras linhagens em formação" (Gifford 1929:30).

Epeli Hau'ofa, sem dúvida, estava certo ao afirmar que os polinésios tinham sua própria estrutura de ampliação do mundo desde muito antes de os europeus tentarem exilá-los em pequenas ilhas perdidas em um mar distante.

Além disso, desde o século XIX, culturas translocais similares às de Tonga e de Samoa vêm se desenvolvendo por todo o Terceiro M undo, entre povos supostamente encarcerados pelo imperialismo e sem nenhuma esperança de "desenvolvimento" 6 . Tomando freqüentemente a forma de postos avançados de bases rurais "tribais" , tais formações étnico-urbanas sintéticas passaram despercebidas como tais, durante muito tempo, pelos cientistas sociais ocidentais. Ou melhor, ao estudar os processos de urbanização, migração, recrutamento de mão-de-obra ou formação étnica, os pesquisadores ocidentais pareciam repetir a parábola dos cegos e do elefante, com cada um satisfazendo-se em descrever a totalidade translocal em termos de apenas este ou aquele de seus aspectos. E no entanto, desde os anos 50, essas comunidades espacialmente descontínuas vinham surgindo por toda parte: em J ava, Sumatra, Kalimantan, nas Filipinas, na Tailândia e em outras partes do Sudeste Asiático; em ilhas espalhadas pelo Pacífico; nas Américas Central e do Sul; no Caribe; na África Oriental, Ocidental, Central e M eridional; no Egito, na J ordânia, na Turquia, e até mesmo em Portugal7.

Os antol hos postos na imaginação antropológica pela história européia foram uma das principais razões pelas quais essa nova estrutura cultural da modernidade permaneceu por tanto tempo conceitualmente indeterminada. O pressuposto geral das ciências sociais ocidentais era o de que a urbanização necessariamente dá fim à "idiotia da vida rural", como teria ocorrido no início da Europa moderna. Pela própria natureza da cidade enquanto organismo social complexo, as relações entre as pessoas deveriam se tornar impessoais, utilitárias, secularizadas, individualizadas, e variamente desencantadas e destribalizadas. Assim era o progresso; essa era a tendência do famoso "continuum folk-urbano" de Redfield. O campo e a cidade, estágios respectivamente inicial e final de uma mudança qualitativa, representavam modos de vida estruturalmente distintos e opostos.

É verdade que fortes argumentos empíricos contra essa visão de uma descontinuidade rural-urbana já haviam sido formulados no início dos anos 60, a partir de estudos sobre as comunidades de imigrantes em cidades não-européias. Edward Bruner criticou explicitamente a perspectiva de Redfield - " com o surgimento das cidades, os homens se tornam dife- 
rentes daquilo que haviam sido antes" -, mostrando as continuidades de identidade, costume e parentesco entre os Toba Batak das aldeias das Terras Altas e seus parentes urbanos em M edan (Sumatra). A descrição feita por Bruner da unidade batak lembra o que já vimos acerca dos samoanos; na verdade, essa descrição estava destinada a se repetir em todo o mundo: "examinadas de um ponto de vista estrutural, as comunidades toba batak nas aldeias e nas cidades são partes de um único sistema social e cerimonial" (Bruner 1961:515; ver, também, Bruner 1959)8. M esmo assim, o dogma da antítese histórica entre aldeia e cidade dificultou uma mudança de Gestalt que permitisse perceber a possibilidade de existência de uma população translocal capaz de habitar ambos os mundos, mantendo-os como partes interdependentes de uma totalidade sociocultural.

A antropologia social britânica na África permaneceu por muito tempo cativa do mesmo a priori dualista. Em 1960, em um influente artigo que resumia vinte anos de pesquisa do Rhodes-Livingstone Institute, $\mathrm{M}$ ax Gluckman fazia da distinção entre "gente da cidade" [townsmen] e "gente da tribo" [tribesmen] uma questão de princípio teórico. "Um africano da cidade é um citadino, um mineiro africano é um mineiro; só secundariamente ele é um membro de uma tribo" (1960:57). Gluckman e seus colegas estavam sempre prontos a contestar o preconceito colonial ista segundo o qual os citadinos africanos eram necessariamente "destribalizados" (cf. M itchell 1956; Epstein 1958)9. M as as "classificações" tribais observadas nas cidades eram distintas, em sua função e implicação comportamental, das do tribalismo rural - distinção que refletia dois sistemas sociais diferentes. "O africano na área rural e na cidade", disse Gluckman, "são dois homens diferentes" (1960:69).

M as enquanto isso, vários estudantes e associados de Gluckman estavam descrevendo algo bem diverso: uma síntese de "gente da cidade" e "gente da tribo" em um único campo sociocultural, síntese que construía sua identidade a partir das origens tribais no campo e que valorizava estas origens - o que inibia ou impedia a transformação dos imigrantes em um proletariado urbano típico. Era isso que mostravam M ayer (1961; 1962) sobre os Red Xhosa; Van Velsen (1960) sobre os Tonga da Niasalândia; e Gulliver (1957) sobre os Nyakusa. O livro Tribal Cohesion in a M oney Economy, de Watson, inaugurou, além disso, o estudo comparativo de estruturas translocais, mostrando como o sistema patrilinear dos $M$ ambwe fora capaz de extrair rendimentos materiais mais elevados do trabalho dos emigrantes, ao mesmo tempo que mantinha uma maior integridade social, que a ordem matrilocal-matrilinear de seus vizinhos 
Bemba. Entretanto, pode-se avaliar o peso conceitual concedido a tais observações quando as vemos relegadas a uma nota de rodapé do ensaio crítico de Clyde M itchell (1967) sobre as "Theoretical Orientations in A frican Urban Studies". Mitchell diz: "Estou aqui excluindo os estudos sobre migração que vêem a cidade e o campo como partes integrais de um mesmo sistema social em que homens da cidade e homens da tribo estão ligados por redes de relações estabelecidas na cidade, nas áreas rurais, e entre as duas" (1967:161).

Entretanto, como se os encontrava cada vez mais freqüentemente, os sistemas translocais logo se tornariam difíceis de ignorar ${ }^{10}$. A escola do Rhodes-Livingstone foi objeto de críticas explícitas - análogas às objeções empíricas anteriormente feitas ao conceito de continuum folkurbano - por seu dualismo entre homens citadinos e homens tribais (Ross e Weisner 1977; Hart 1971; Mayer 1961; 1962)11. Entre outros problemas, a antítese entre citadinos e tribais não era normalmente reconhecida pelas pessoas em causa - sequer pelos que já residiam há muito tempo na cidade, e que eram membros de sindicatos trabalhistas ou outras associações urbanas; eles não abandonavam suas afiliações tribais ou suas relações com a base rural. Assim, um estudo após o outro (e não apenas na África) começaram a tratar da união dos habitantes das aldeias com seus parentes da cidade em "uma sociedade bilocal", "um campo social comum", "um sistema social e econômico comum", "uma aldeia social espalhada por milhares de quilômetros", "uma rede comunitária não-territorial", uma "estrutura social que abarca os pólos de emigração e de imigração" , ou alguma coisa do gênero (Ryan 1993:326; Ross e Weisner 1977:361; Trager 1988:194; Uzzell 1979:343; Whiteford 1979:127; Bartle 1981:105)12. De fato, vários pesquisadores perceberam que os setores metropolitano e interiorano desse sistema unificado mostravam uma tendência a se tornar cada vez mais semelhantes entre si, e isso não apenas porque o fluxo de idéias e de mercadorias provenientes da cidade estaria transformando o campo.

A modernização, com efeito, não tem sido a única alternativa, sequer na cidade. O efeito inverso, a indigenização da modernidade, é no mínimo tão acentuado quanto o primeiro - na cidade como no campo. $\mathrm{Na}$ complexa dialética da circulação cultural entre a terra natal e os lares alhures, as práticas e relações tradicionais ganham novas funções e talvez novas formas situacionais. Assim, Van Velsen, estudando os Tonga da Niasalândia, chegou à interessante conclusão de que os trabalhadores migrantes retornados, ao competirem por posições políticas e assumirem direitos fundiários locais - para o que precisavam contar com a ajuda 
dos parentes - , "estimulavam ativamente os valores tradicionais de sua sociedade rural" (1960:278)13. Para os Tonga africanos, como para os polinésios de Tonga, o parentesco é, freqüentemente, antes um beneficiário que uma vítima da modernização - em contraste, mais uma vez, com a experiência dos europeus e com sua ciência social normal. A riqueza da cidade subsidia as relações na aldeia, ao mesmo tempo que os parentes na cidade organizam a emigração da aldeia. Em pesquisas pioneiras que, realizadas nos anos 60 , antecipavam muito do que se verificaria mais tarde, Keith Hart mostrava que a integração dos Frafra (Tallensi e povos congêneres de Gana) rurais e urbanos se fez em grande parte por meio de seu sistema clássico de linhagens. Hart concluía daí que era necessária uma nova perspectiva antropológica, capaz de transcender as oposições correlativas entre o moderno e o tradicional, o homem citadino e o homem tribal, o urbano e o rural. Em troca, ela propunha a idéia de uma "expansão dos horizontes da comunidade":

“Essa expansão dos horizontes da comunidade, em termos da distribuição física dos indivíduos que se concebem como membros de um agregado socialmente definido, tal como uma linhagem, faz com que não mais seja tão simples estabelecer uma dicotomia, pelo menos espacial, entre os aspectos tradicional e moderno, ou mesmo rural e urbano, da vida atual dos Frafra. $\mathrm{O}$ mundo do imigrante e o da terra natal não são entidades separáveis [...]. A dificuldade de se distinguir o antigo do novo na sociedade Frafra contemporânea, seja no contexto nacional da Gana moderna, seja no contexto local da área tribal de origem, é ilustrada pela participação simultânea da maior parte dos Frafra em ambas as culturas, pela troca mútua de pessoal entre a aldeia natal e a cidade sulista, pela urbanização interna do próprio distrito frafra, pelo caráter generalizado da economia de mercado, e especialmente pela facilidade de comunicação entre todas as partes do país. Com a diminuição das descontinuidades entre a vida na cidade e a vida na aldeia, que sentido podemos atribuir a tipos como 'homens da cidade' e 'homens do campo'?" (1971:26)14.

A rrisco, a seguir, algumas generalizações sobre a estrutura desses sistemas translocais tais como descritos por Hart, Hau'ofa e tantos outros. Culturalmente focalizada na terra natal, e estrategicamente dependente dos lares periféricos no estrangeiro, a estrutura é assimétrica de duas maneiras opostas. Considerada como uma totalidade, a sociedade translocal está centrada em suas comunidades indígenas e orientada para elas. Os imigrantes identificam-se com seus parentes na região de origem, e é 
a partir dessa identificação que se associam transitivamente entre si no estrangeiro. Esses habitantes da cidade e do mundo exterior permanecem ligados a seus parentes na terra natal, especialmente por entenderem que seu próprio futuro depende dos direitos que mantêm em seu lugar de origem. Assim, o fluxo de bens materiais favorece em geral os que ficaram em casa: estes se beneficiam dos ganhos obtidos e das mercadorias adquiridas por seus parentes na economia comercial externa. Nas palavras de um pesquisador, a aldeia consegue reverter "a função parasita tradicionalmente atribuída às cidades" (Hugo 1978:264). Sob esse aspecto, portanto, a ordem indígena engloba a moderna.

Enfatizo que as sociedades transculturais têm seu foco na terra natal, e que sua forma de vida possui um caráter espacialmente centrado, para me contrapor a uma tendência a se falar em "desterritorial ização" e em uma ligação "meramente simbólica" ou "imaginária" dos povos da diáspora com seus lugares de origem. A condição originária da terra natal também é pertinente: a estrutura tem dimensões temporais bem como espaciais. Em contraste com essa idéia, vários antropólogos, nos últimos anos, impressionados pelo modo como essas comunidades multilocais são capazes de transcender a territorialidade, muitas vezes ultrapassando fronteiras nacionais, argumentaram que elas seriam melhor compreendidas como ordens não-espaciais, e que é nisso precisamente que residiria sua novidade. Roger Rouse (1989) avançou, assim, a interessante sugestão de que a comunidade, no caso dos imigrantes mexicanos nos Estados Unidos, não apenas se exprime, mas se constitui na própria circulação naquilo que ele chama de um "circuito de migração transnacional". Outros, como Arjun A ppadurai, visando à realidade do amplo movimento das populações, desvalorizaram a permanência da identificação com a terra natal. Esta, escreve A ppadurai, "é em parte inventada, existente apenas na imaginação dos grupos desterritorializados, e às vezes se torna tão fantástica e simplificada que chega a desencadear novos conflitos étnicos" (1991:193). Tal observação é pelo menos salutar, ao inverter as costumeiras lições de moral do objetivismo, por sugerir que um dado fato social ou identidade podem ser reais o bastante para que as pessoas morram por sua causa (cf. Ashmore, Edwards e Potter 1994)15. Outro exemplo do realismo empírico implícito na perspectiva da desterritorialização é dado por Gupta e Ferguson, para quem a aparente liberdade espacial é tão "real" que a valorização da terra natal parece, por contraste, simbólica, quando não também irônica: 
“A ironia dos tempos que correm [...] é que, conforme os lugares e localidades reais vão se tornando cada vez mais vagos e indeterminados, as idéias de lugares cultural e etnicamente distintos se tornam talvez mais conspícuas [...]. A 'terra natal', desse modo, permanece como um dos mais poderosos símbolos unificadores para pessoas móveis e deslocadas [...]. Precisamos abrir mão das idéias ingênuas da comunidade entendida como uma entidade literal, mas continuar sensíveis à profunda 'bifocalidade' que caracteriza as vidas vividas localmente em um mundo globalmente interconectado" (1992:1-17).

Pode-se ver que o reconhecimento da sociedade transcultural custou algum esforço à imaginação antropológica. Sem entrar na metafísica das entidades e das espacialidades, deve-se notar que a comunidade ampliada também possui a qualidade necessária da temporalidade, que é de onde extrai sua consistência cultural. É precisamente enquanto lugar de origem que a terra natal permanece como foco de um amplo espectro de relações culturais. Fonte de valores e identidades herdadas, a comunidade natal transcende outras fronteiras culturais, conformando as ações e atitudes da parcela de seu povo que vive em contextos urbanos e/ou estrangeiros. Comentando um estudo dos Siane em Port M oresby (Nova Guiné), Richard e M ary Salisbury observaram que, contrariamente às idéias correntes sobre a "urbanização" de imigrantes, muitos dos Siane, provenientes das Terras Altas, adaptaram-se com sucesso à cidade sem perder o campo de vista: "seus objetivos permanecem os mesmos de antes. Quando na cidade, suas estratégias de escolha entre comportamentos alternativos continuam a ter como meta o máximo de sucesso possível no contexto rural, e são condicionadas pelas opções disponíveis nas aldeias" (1972:59). As pessoas, como descobriram os Salisbury, percebem o valor da vida na aldeia, e querem retornar para lá, “levando consigo as vantagens da cidade".

Essas "vantagens da cidade" exprimem a assimetria complementar presente na sociedade transcultural, implicando uma certa superioridade do setor moderno e externo. Além das virtudes materiais dos bens estrangeiros, os objetos e experiências do mundo exterior são incorporados nas comunidades natais como poderes culturais. Eles exercem influência positiva sobre as relações locais, desempenhando papéis críticos para a reprodução das sociedades natais ${ }^{16}$. As migrações estrangeiras articulam-se assim às ambições locais. Tudo isso pode ser visto de maneira precisa nos casos em que as trocas entre os lares al hures e o povo da terra natal são assimiladas às práticas tradicionais de reciprocidade (Hau'ofa 
insiste ser essa a correta compreensão de tais transações). Pois, se os bens de fora evocam reciprocamente direitos e atenções em casa, para além de qualquer bem ou hospitalidade indígena oferecido em retorno, é porque as contribuições dos emigrantes têm efeitos poderosos sobre as relações locais. Funções-chave tradicionais, tais como trocas matrimoniais e mortuárias, festas e rituais de vários tipos, transmissões de descendência e de títulos são subsidiadas pelos rendimentos obtidos no setor comercial externo. Assim, o centro indígena torna-se dependente, para sua reprodução cultural - ou, talvez, para um certo develop-man -, das pessoas que moram no exterior ${ }^{17}$.

Valores de prestígio e poder residem na esfera estrangeira: em seus seres, seus objetos e nas coisas que lá se fazem. O desenvolvimento das sociedades transculturais, portanto, parece ter uma relação significativa com o fato de que muitos povos concediam tais virtudes às esferas e modos de existência estrangeiros muito antes do colonialismo apresentálos a versões mais draconianas. Vários etnógrafos modernos, trabal hando em lugares tão distantes entre si como o M éxico, a Amazônia, a Indonésia, a N ova Guiné e Vanuatu, fizeram interessantes associações entre as migrações circulares antigas e modernas. Tradicionalmente, as expedições podem ter sido ritos de iniciação - observação feita em 1947 por Schapera, a propósito da África do Sul (M acpherson 1985:242)18. Retornando de proezas que transcendiam as fronteiras culturais e comunitárias, os homens traziam troféus de guerra ou de caça: bens ganhos em pilhagens ou nas trocas, visões, canções, danças, amuletos, curas e cultos, objetos familiares ou insólitos que pudessem ser consumidos, sacrificados, trocados ou variamente distribuídos para renovar e desenvolver as formas indígenas de vida. Certas disposições para o englobamento cultural que hoje são conhecidas como "imperialismo" não nasceram ontem; as sociedades não-ocidentais tampouco eram tão limitadas e autocontidas como o pós-modernismo supõe que o modernismo supõe.

"Assim como o cego Homero cantava as viagens e proezas de Ulisses e dos heróis de Tróia," observa Roderic Lacey, "assim também os poetas Enga [da Nova Guiné] louvaram seus heróis e imortalizaram seus feitos através de cantos comemorativos" (1985:93). Se a poesia persiste, é porque os europeus "abriram novos caminhos para os viajantes indígenas". Podemos dizer que, da diáspora inicial do período colonial, passando pelas "viagens e visões épicas nascidas da guerra no Pacífico", até a diversificação das oportunidades e destinações na época pós-colonial, a Nova Guiné assistiu a um developman exponencial da tradição das viagens. Nesse sentido, os jovens que partem para as cidades costeiras ou 
para terras estrangeiras em busca de educação, emprego e aventura serão, de maneira algo semelhante às odisséias dos antigos, fontes de inovação e transformação da existência indígena ${ }^{19}$. Assim também, na Indonésia, o costume do merantu continua com a importância de sempre. Os jovens ainda empreendem longas viagens, com o objetivo de passar pelas experiências que os tornarão merecedores do status de adulto (Provencher 1976). Em Oaxaca (M éxico), por sua vez, a migração para os Estados Unidos e o retorno à terra de origem reencenam certas "histórias populares subversivas", cujos heróis "freqüentemente eram ladrões de gado, contrabandistas e amantes ardilosos, todos célebres por sua astúcia e habilidade em transgredir os limites estabelecidos pelos poderosos" (Rouse 1989:124).

E assim nossa própria discussão fecha o círculo, retornando aos imigrantes de Tonga descritos por Epeli Hau'ofa, que, como seus deuses e heróis ancestrais, vêm e vão através de seu mar de ilhas, cruzando obstinadamente as fronteiras internacionais e as barreiras ideológicas a seu "desenvolvimento" erguidas pelos poderes globais constituídos.

M as a sociedade transcultural moderna também gera suas próprias forças ideológicas, seus próprios folclores do interior e do exterior, com uma capacidade semelhante de distribuir pessoas e bens entre esses pólos. Tanto a cidade como o campo conhecem suas contradições - as tensões sociais exacerbadas por sua interdependência - e, em conseqüência disso, atribuem valores positivos complementares ao modo de vida alternativo. A reprodução da sociedade doméstica através da emigração freqüentemente se faz acompanhar de tensões intergeracionais. Os jovens deixam a casa e saem para o mundo. Além dos atrativos da modernidade, a cidade é percebida no campo como um lugar de liberdade - em especial, liberdade diante dos mais velhos e das limitações do costume. E contudo, os efeitos socioculturais centrífugos provavelmente serão refreados pela experiência urbana: vítima da discriminação, da proletarização e da pauperização, uma parcela significativa do componente de origem "tribal" do setor moderno desenvolve uma visão nostálgica de seus lugares ancestrais. Vista da perspectiva da metrópole estrangeira, a terra natal é idealizada como o lugar de um estilo de vida "tradicional", onde todos compartilham seus bens, onde ninguém morre de fome, onde nunca se precisa de dinheiro. Produtos ideológicos do sistema intercultural, as visões respectivas que os setores moderno e tradicional têm um do outro mantêm a circulação entre eles 20 .

Mas essa circulação irá durar? Poderá durar? Supondo que os migrantes se estabeleçam permanentemente no estrangeiro, a sociedade 
transcultural não teria uma espécie de meia-vida geracional, com as ligações com a terra natal progressivamente se dissolvendo a cada geração nascida na cidade ou no estrangeiro? A aculturação dos que moram no exterior não tornaria, mais cedo ou mais tarde, a diáspora irreversível, partindo em pedaços a sociedade translocal? É provável que isso aconteça com al guma freqüência, mas talvez não tão rápida ou facilmente quanto tendemos a acreditar.

Em J ava, a migração circular parece ter estado na moda desde 1860; um estudioso holandês, Ranneft, que pesquisou o fenômeno em 1916, considerou que ele impedia a formação de um proletariado local estável, uma vez que os migrantes introduzidos no modo de produção capitalista permaneciam sendo "homens tradicionais", mantendo um forte envolvimento com suas aldeias de origem (Chapman e Prothero 1985:6; ver Hugo 1982: 72). Em um artigo intitulado "Is a Proletariat Emerging in Nairobi?", W. Elkan (1985) chegou a conclusões muito semelhantes sobre a África mais de um século depois. Muitas das ordens tribais rural-urbanas do continente, tendo se estabelecido nos anos 20 ou mesmo antes, já estavam em sua segunda ou terceira geração quando despertaram a atenção dos pesquisadores ocidentais. E embora, recentemente, "homens de tribo" tenham trabalhado nas cidades por períodos mais longos, às vezes durante toda a sua vida ativa, eles permanecem tão envolvidos - social, moral e economicamente - com seus lugares de origem quanto antes (Gugler 1969:146). O que os estudos sobre os Luo e os Kikuyu em Nairobi mostram, sobretudo, é que o interesse e o investimento na terra natal é diretamente proporcional ao status, à estabilidade e à remuneração recebidos no emprego urbano. As pessoas mais bem-sucedidas na cidade são as mais envolvidas na ordem tradicional do campo, pois são as que têm mais condições financeiras para isso (Parkin 1975a; 1975b; Elkan 1985; Ross e Weisner 1977)21.

Ou ainda, consideremos um exemplo da Nova Guiné: os Uritai residentes em Port M oresby, com que Dawn Ryan (1989) tem trabal hado desde os anos 60. Nos anos 90, três quartos dos Uritai haviam nascido em uma cidade, ou estavam ausentes da aldeia há muito tempo. Seus direitos sobre a terra de origem haviam expirado, e Ryan era da opinião que eles não tinham, concretamente, nenhuma chance de voltar à aldeia. Não obstante, ainda eram "Uritai", e interagiam de modo intenso com os aldeãos de sua terra de origem - muitos dos quais, por sua vez, continuavam a migrar para a cidade. "Os laços primários entre a aldeia e a cidade não sofreram processo algum de enfraquecimento" (Ryan 1993:232). Este parece ser um fenômeno muito comum. Uma vasta literatura antropológica sobre cultura e desenvolvimento indica que "os migrantes não 
têm se proletarizado em nenhum sentido ideológico profundo" (Kearney 1986:352).

A credito que o segredo do aparente fracasso da urbanização dos migrantes é que não houve um estiolamento progressivo e concomitante da vida aldeã. A sociedade translocal pode perfeitamente persistir enquanto houver um diferencial cultural entre o rural e o urbano, ou, de modo mais geral, entre a terra natal indígena e os lares metropolitanos no exterior. Os dois setores permanecerão então interdependentes e culturalmente centrados na terra natal. É bem verdade que uma fração da população migrante pode distender suas conexões com a comunidade de origem. M as ela será substituída por novos grupos vindos da aldeia, e, em troca, uma parte dos que moram na cidade ou no ultramar, desiludidos pela discriminação ou pelo desemprego, ou então prestes a se aposentar, pensarão em "voltar às origens" (ver adiante). Contas feitas, o sistema translocal poderia se auto-reproduzir por um período considerável de tempo. A história da urbanização ocidental não necessariamente se repete, sobretudo se considerarmos que, desde a Antiguidade, essa história vem sendo escrita a partir de uma distinção discriminatória entre o bárbaro e o civil(izado) que praticamente inverte o valor cultural do mundo rural ou interiorano vigente nas comunidades translocais modernas.

Nesse sentido, já vimos aqui algo dos danos causados por aquela ilusão da história ocidental que toma certas características da urbanização - relações impessoais, individualismo, declínio do parentesco extensivo, secularização etc. - por efeitos inerentes da cidade enquanto ordem sociocultural. Mas, ainda que brutal e estúpida, não teria sido a dissolução cultural da vida rural uma condição necessária para que a cidade pudesse realizar sua mágica modernizadora? Quer pelo fechamento dos campos, abolição dos estatutos sociais tradicionais ou outras formas de despovoamento, quer pela integração econômica e política do campo, a terra de origem pode não ser mais capaz de funcionar como fonte de identidade e como alternativa significativa. A persistência da cultura rural, mais que a existência da cultura urbana, é aparentemente a chave da continuidade das comunidades translocais. E se, em virtude da destruição que se abateu sobre o campo, certos regimes, como o sul-africano, conseguiram de fato produzir uma alienação suficiente para urbanizar e proletarizar suas populações tradicionais, resta que, para a maior parte dos povos indígenas do Terceiro M undo, as cidades modernas para as quais eles migraram são dupla ou triplamente alienantes. Estrangeiras em sua cultura, estranhas também enquanto sedes das instituições estatais, as cidades são além disso o espaço dos clássicos estranhamentos ine- 
rentes à produção capitalista. Dadas todas essas fraturas, a cultura translocal, enquanto forma de vida distintiva da modernidade, pode ainda ter uma longa história pela frente.

Talvez muita longa mesmo, pois as sociedades translocais estão se associando com o poderoso movimento de autoconsciência que varre hoje o planeta. Todos os paradoxos da história mundial contemporânea, todas as oposições que acreditávamos serem excludentes, como aquelas entre tradição e modernidade, ou entre mobilidade e continuidade, estão se fundindo em novas sínteses culturais. Consideremos esta observação feita por um estudioso das sociedades melanésias:

\begin{abstract}
“Hoje a identidade dos povos melanésios não emerge como uma ruptura com o passado, mas como uma continuidade. No entanto, não se trata de uma mera repetição do passado; a mobilidade, mesmo a circular, ampliou horizontes. Novas solidariedades surgiram [...] as sociedades insulares [...] foram penetradas pela economia monetária internacional e passaram a se inscrever em espaços mais vastos [...]. O debate atual não mais diz respeito à resistência da sociedade melanésia diante das influências do Ocidente, tema antes dominante, mas sim às escolhas a serem feitas em vistas do desenvolvimento socioeconômico e às formas pelas quais ele reverte para a sociedade. A grande surpresa para os que a vêem de fora, sem dúvida, é a capacidade de esta sociedade se recriar à sua própria imagem a partir de um complexo de diversos padrões conceituais e realidades político-econômicas" (Bonnemaison 1985:60-61)22.
\end{abstract}

\title{
Terence Turner: o "culturalismo" contemporâneo
}

Por muito tempo, Terence Turner defendeu uma visão instrumental e histórica da cultura, em contraposição a concepções correntes que fariam dela uma ordem simbólica autodeterminante, dissociada de sua gênese na ação social e na intencionalidade humana. Para Turner, a cultura é precisamente "o sistema de formas significativas de ação social", portanto, "ela deve ser entendida, essencialmente, como o meio pelo qual um povo define e produz a si mesmo enquanto entidade social em relação à sua situação histórica em transformação" (Turner 1987:6). Turner também argumentou por muito tempo a favor da capacidade de ação [agency] histórica dos povos indígenas em face do sistema mundial capitalista, opondo-se à visão que os desumaniza e ignora suas lutas, ao tomálos como meros pacientes e objetos da dominação ocidental23. Uma das 
ironias do discurso hoje em voga sobre a alteridade, observa Turner, "é que ele tende a exagerar o poder que teriam as representações ocidentais de se impor aos 'outros', dissolvendo suas subjetividades e objetivando-os como meras projeções do ol har desejante do ocidente dominador". M ais ainda, tal pessimismo antropológico mostra a mesma distância da ação e a mesma ignorância da história que têm tão freqüentemente marcado os conceitos de cultura de nossa disciplina. A antropologia revelase, assim, incapaz de dar conta do que ela própria tantas vezes constatou, a saber, que

“[...] em virtualmente todas as situações de contato entre povos tribais e sociedades nacionais ocidentalizadas, uma parte significativa das transformações sociais e culturais da sociedade nativa não é mero resultado da opressão exercida aberta e deliberadamente pela sociedade nacional ou da exploração levada a cabo pelos representantes do capital internacional, mas é, ao contrário, objeto de um consentimento ativo, isto quando não é espontaneamente desencadeada pelos próprios povos indígenas" (Turner 1979:8).

Durante um certo tempo, Turner também insistiu no fato de que a "sobrevivência cultural"* no mundo moderno consiste na tentativa dos povos se apropriarem desse mundo em seus próprios termos. Não se trata, como muitos supuseram, de um desejo nostálgico de teepees e tomahawks ou de qualquer outra encarnação fetichizada do sentido da cultura. Tal suposição, que traduz "uma tentativa ingênua de manter os povos indígenas como reféns de um momento de sua própria história", redunda justamente, observa Turner, em privá-los da história (1987:7).

Como a maioria de nós, entretanto, Terence Turner acabou chegando a uma concepção mais sofisticada de cultura a partir de uma crítica de seu próprio passado. Quando foi pela primeira vez à A mazônia, em 1962 - conforme relata em um artigo recente cujo subtítulo é "Transformações Históricas da Cultura Kayapó e da Consciência A ntropológica" —, nem ele nem os índios entendiam sua "cultura" ou sua situação histórica do modo como o fazem agora (Turner 1991). Em 1962, os Kayapó da aldeia Gorotire pareciam viver uma vida dupla, uma verdadeira esquizofrenia entre o indígena e o moderno. Seu modo de existência tradicional, sua inscrição espaço-temporal e seu conceito de pessoa estavam relega-

\footnotetext{
* N.T. - Faz-se aqui uma alusão ao nome de uma ONG norte-americana bastante conhecida, a "Cultural Survival".
} 
dos aos exíguos limites traçados pelas exigências "civilizatórias" da sociedade brasileira envolvente. Dependendo dos funcionários da agência oficial de proteção aos índios e de missionários cristãos para a obtenção de remédios, armas, munição e outras mercadorias vitais, eles pareciam não ter disposição alguma para agir de outro modo; por iniciativa própria, tiravam seus estojos penianos e batoques labiais e vestiam roupas ocidentais sempre que isso parecia apropriado; igualmente, adaptavam suas cerimônias às restrições espaciais e cosmológicas impostas pela nova aldeia de tipo brasileiro onde haviam sido obrigados a se estabelecer*. $M$ as as duas culturas que eles assim viviam não pareciam ter qualquer relação entre si; como tampouco, aliás, segundo a cosmologia tradicional, os brancos e seu modo de vida absurdo poderiam ser equi parados à humanidade "bela" e "completa" dos Kayapó. Desse modo, a cultura oriunda das esferas nacional e internacional assemelhava-se a "um verniz alienígena sob o qual a autêntica cultura kayapó ainda persistia" (Turner 1991:291). As formas indígenas persistiam apesar do contato interétnico, "e não devido a uma acomodação estável e harmoniosa a ele" (Turner 1991:291). E, certamente, a situação caracterizava-se pela subordinação dos Kayapó, se não por sua humilhação.

Assim, em 1962, a etnografia mimetizava-se em arqueologia, descartando as camadas superficiais, modernas e revoltas, do solo da aculturação em busca dos vestígios mais profundos do índio autêntico. Turner salienta a peculiar cumplicidade entre esse tipo de antropologia e o que ela tinha por seu objeto de estudo. Como a cultura kayapó, a antropologia daquele período se definia “fazendo abstração da 'situação de contato', pensando-se como a antítese da 'transformação' e como a inimiga da 'história'” (Turner 1991:292). As concepções estáticas de cultura que a antropologia havia herdado de seus ancestrais estrutural-funcionalistas e congêneres só encontravam similar na aparente incapacidade kayapó de tomar consciência de sua cultura - isto é, dessa cultura como produto social dos próprios Kayapó - e de usá-la reflexivamente como arma contra as forças e instituições externas que os oprimiam. Sem conseguir objetivar sua cultura e conferir-lhe um valor instrumental, os Kayapó tampouco podiam fazer de sua identidade étnica uma afirmação de autonomia.

Embora no final nos anos 70 Terence Turner já afirmasse que um conceito consciente de cultura seria um recurso poderoso na luta dos povos

\footnotetext{
* N.T. - O autor refere-se ao abandono da planta circular tradicional e à construção de uma aldeia em "arruados" lineares, ao modo dos vilarejos brasileiros.
} 
indígenas pela "sobrevivência cultural", em meados dos anos 80 ele ainda se mostrava pessimista quanto às chances de os Kayapó adquirirem a necessária autoconsciência. De fato, em 1976, ele havia tentado explicitamente transmitir aos Kayapó uma concepção instrumental de cultura mas eles não haviam captado a idéia. Estavam muito longe de apreendêla e de poder aplicá-la à sua situação, constatava Turner em um texto escrito em 1986. "Não estou dizendo que isso seria impossível", continuou, "mas apenas que, para um povo como os Kayapó, que não têm nenhuma concepção crítica de sua própria cultura, isso não seria nada fácil".

No entanto, ao retornar a Gorotire em 1987, aproximadamente 25 anos depois de seu primeiro trabal ho de campo, tudo havia mudado. A palavra "cultura"* agora era ouvida com freqüência. Ela estava associada a uma relação inteiramente nova com os outros povos indígenas, com a sociedade nacional e o sistema internacional. Os Kayapó estavam envolvidos ativa e criativamente no campo interétnico, com os olhos postos na apropriação de seus poderes e produtos tendo em vista a reprodução de sua própria "cultura". Eles agora entendiam sua cultura - incluindo as técnicas de subsistência, a dieta alimentar, as cerimônias, as instituições sociais, o acervo de saberes e costumes - como necessária à sua "vida", "força" e "felicidade". Era comum, Turner escreve,

“[...] ouvir líderes kayapó, bem como homens e mul heres comuns, dizendo ter como motivação fundamental de sua luta política a manutenção de seu modo de vida cultural e a defesa deste contra pressões de assimilação e de destruição por parte da sociedade nacional. Muitos, inclusive indivíduos monolíngües, haviam começado a usar a palavra portuguesa 'cultura' para se referir ao seu modo de subsistência material, ao ambiente natural ao qual está essencialmente ligado, bem como às suas instituições sociais e ao seu sistema cerimonial tradicional. $\mathrm{O}$ termo nativo para o conjunto de saberes e costumes, kukràdjà [que significa algo que se leva muito tempo para contar], era agora também comumente empregado da mesma forma, isto é, para se referir às práticas e saberes tradicionais como al go que exigia um esforço consciente por parte da comunidade para sua preservação e reprodução" (1991:304).

M ais uma vez, isso não significa uma volta ao estado de natureza (ou de uma cultura primordial). A reprodução da cultura kayapó agora

* N.T. - Em português no original. 
depende da capacidade de se domesticarem os meios e controlarem as forças de sua transformação histórica. Os Kayapó não recusam a história: eles se propõem a responder por ela; pretendem orquestrá-la segundo a lógica de seus próprios esquemas. Vale a pena repetir: na luta contra o Leviatã moderno, a continuidade das culturas indígenas consiste nos modos específicos pelos quais elas se transformam.

Turner (1992) fornece um bom exemplo disso em sua brilhante análise do uso que os Kayapó fazem do vídeo. Por um lado, os Kayapó voltam a câmera para as forças externas que os ameaçam, documentando as atividades dos funcionários do governo e congêneres - e cuidando, ao mesmo tempo, para que essa documentação seja ela mesma registrada em documentários dirigidos ao público internacional. Por outro, criando um arquivo em vídeo de suas próprias cerimônias, eles Ihes conferem materialidade e permanência históricas. N essa produção para consumo interno, Turner mostra detal hadamente como o trabal ho de câmera e de edição dos Kayapó responde à sua noção tradicional de "beleza" que é precisamente a transformação da natureza em cultura. $\mathrm{O}$ meio, portanto, é a mensagem: a dependência dos Kayapó em relação à sociedade brasileira se vê agora contrabalançada por uma oposição vigorosa a esta sociedade - em nome da "cultura" indígena kayapó24.

De fato, nas relações diretas com o governo nacional e com as forças internacionais, os Kayapó, sempre sob a bandeira de sua "cultura", estão tomando as devidas providências quanto à sua situação de subordinação. Como Turner (1993:3) testemunhou, eles estão “assumindo o controle da estrutura institucional de dependência". Os moradores de Gorotire agora dirigem o escritório regional da Funai. Eles compraram ou alugaram casas em cidades importantes do Pará, e viajam a Belém em avião próprio para fazer compras e inspecionar a venda de sua castanha-do-Pará. As mercadorias que os índios trazem de avião para a aldeia são, em geral, compradas com os fundos depositados em gordas contas bancárias (abertas em nome da comunidade ou dos chefes) abastecidas pelos royalties do ouro e da madeira extraídos de seu território. Além do avião, os moradores de Gorotire possuem dois caminhões, um automóvel e vários barcos a motor. A farmácia e enfermaria locais são dirigidas por paramédicos nativos que trabalham em conjunto com os médicos brancos a serviço da aldeia. Os missionários estrangeiros não atuam mais abertamente em Gorotire, e quem dirige os serviços dominicais é um índio convertido. Os Kayapó estabeleceram postos de vigilância nas fronteiras de suas reservas, guarnecidos por equipes compostas em geral de jovens solteiros, em regime de revezamento. Além disso, os índios policiam e administram 
dois grandes garimpos de ouro na área, regulando a quantidade de metal extraído com o objetivo de proteger os royalties que obtêm com a exploração. “Em suma, durante esta última década, os Kayapó de Gorotire assumiram sistematicamente o controle de todos os focos institucionais e tecnológicos de dependência em relação à sociedade brasileira existentes dentro de sua comunidade e seu território" (Turner 1993:5).

As iniciativas político-culturais dos Kayapó não são exclusivas desse ou de outros povos da Amazônia. São antes expressões locais de um fenômeno mundial. Avaliando as Iutas pelos direitos indígenas na Austrália, Canadá e Nova Zelândia, David Pearson faz reflexões que se harmonizam perfeitamente com as palavras de Turner sobre os Kayapó:

\begin{abstract}
“Em todos os três países, a luta pela autodeterminação indígena mostra um esforço para assumir o controle da administração oficial das reservas, bandos ou tribos, transformando-a em fonte de recursos políticos para os povos nativos. Essa luta inclui a substituição de administradores 'brancos' por pessoal nativo, a busca de maior controle político e econômico sobre a terra e os recursos naturais, e a invenção de um novo lugar simbólico dentro das estruturas estatais, conferindo aos nativos o estatuto especial de 'cidadãos com direitos adicionais' ['citizens plus']. Os povos indígenas desejam ter pleno acesso a todas as áreas da sociedade, ao abrigo de preconceitos e discriminações, como os demais cidadãos. $M$ as eles também reclamam um estatuto especial de originariedade ou aboriginalidade, com seu próprio conjunto de direitos e obrigações" (1994:137-138).
\end{abstract}

Esse tipo de autoconsciência cultural, conjugado à exigência política de um espaço indígena dentro da sociedade mais ampla, é um fenômeno mundial característico do fim do século XX. As antigas vítimas do colonialismo e do imperialismo descobriram sua "cultura". Por muito e muito tempo os seres humanos falaram cultura sem falar em cultura - não era preciso sabê-lo, pois bastava vivê-la. E eis que de repente a cultura se tornou um valor objetivado, e também o objeto de uma guerra de vida ou morte. Não se deve atribuir aos antropólogos e assemel hados toda a culpa ou mérito por esse interesse e respeito inéditos pelas culturas nativas. M uitos povos foram antropologizados durante décadas sem que por isso objetivassem e celebrassem sua cultura; e muitos outros vieram a se tornar conscientes de sua cultura sem o auxílio da antropologia. A "cultura" - a palavra mesma ou algum equivalente local - está na boca do povo, sobretudo no contexto das forças nacionais e globais que ameaçam os modos tradicionais de existência do(s) povo(s). E se toda determinação é uma nega- 
ção, é interessante que a negação da cultura - o contraste que a determina - seja tão freqüentemente o conjunto de valores econômicos trazidos com o capitalismo. Recordemos como os nativos de Fiji opõem "viver à maneira da terra" (bula vaka vanua) e "viver de/por dinheiro" (bula vakailavo), ou como os povos da N ova Guiné contrastam kastom e bisnis*.

Essa oposição, entretanto, é relativizada na prática, pois, como já vimos, o bisnis tem caracteristicamente por meta o developman do kastom. Os meios são modernos, bisnis, mas os fins são indígenas, como, por exemplo, a extensão do parentesco através da troca tradicional. Ou ainda, como ocorre na ilha de Páscoa, a contradição é sintetizada pela criação de uma "Corporação para a Proteção Cultural", que resistiu com sucesso a vários projetos indesejáveis do governo colonial chileno. "Somos diferentes dos chilenos na língua, na cultura e no modo de pensar", diz o fundador da assim chamada corporação, Rodrigo Paoa. Ele continua: "como Rapanui**, se quero dormir, durmo. Se quero comer, como. Posso passar uma semana inteira sem gastar nenhum dinheiro. Se não tomarmos cuidado, esta ilha será transformada em um novo Havaí ou Taiti, onde a única coisa importante é o dinheiro" ( $N$ ew York Times International: 6/2/1993).

Poder-se-ia pensar que os nativos da ilha de Páscoa, notoriamente escravizados, dizimados e colonial mente inferiorizados, seriam uma evidência impecável a favor da teoria do desalento. Bem, talvez isto seja certo para os habitantes da ilha de Páscoa, mas não para os de Rapa Nui. De fato, um relato etnográfico recente feito por Grant M cCall apresenta algumas experiências radicais de renascimento cultural. Coincidindo com o centenário de anexação da ilha pelo Chile, o Conselho dos Chefes da Ilha de Páscoa, "organização não-governamental comunitária", deu-se ao trabalho de publicar genealogias completas de todos os Rapanui vivos. 0 propósito era dividi-los em vinte ure (grupos de parentesco territorializados). M esmo antes de a publicação vir à luz, de acordo com M cCall (1994:70), as pessoas já haviam começado a reivindicar sua pertença a essas linhagens. $O$ jogo só acaba quando termina.

Também os havaianos vêm reivindicando seus direitos perante o mundo em nome de sua cultura tradicional; e assim também os aborígines australianos, os Inuit, Ojibwa, Iroquois, Swazi, Ibo, Iban, Sami, Yakut, malaios - povos de todos os cantos do Terceiro e do Quarto M undos. A

\footnotetext{
* N. T. - Termos neomelanésios derivados, respectivamente, do inglês custom (costume ou cultura) e business.

** N. T. - Nativo de Rapa Nui, a ilha de Páscoa.
} 
humilhação cultural infligida no período colonial não pesa mais sobre esses povos como outrora. Assim como os Rapanui, muitos se desfizeram dos nomes adquiridos durante o período colonial, reassumindo suas identidades aborígines. As difamações do passado "pagão" pré-europeu, de inspiração colonialista, também estão saindo de moda - especialmente entre os mais jovens. Numa curiosa inversão de papéis, as gerações mais jovens são com freqüência defensoras da "tradição" e promotoras de seu renascimento. É de se esperar que elas estejam enfrentando alguma oposição por parte daqueles entre os mais velhos que se haviam acomodado aos brancos e internalizado sua reprovação aos modos de vida ancestrais. M as agora, como observou Lamont Lindstrom (1982:325) sobre os ilhéus de Tanna (Vanuatu), a contradição moral entre kastom e modernidade está entrando em colapso (ver, também, Warren 1992) ${ }^{25}$.

Também é apenas aparentemente contraditório o fato de que alguns dos mais eminentes defensores da cultura tradicional sejam sofisticados estudiosos da ordem mundial ocidental. Com freqüência, eles são as pessoas mais "aculturadas", como aquele artista e autodesignado "praticante cultural" [cultural practitioner] de Zuni, que decora as paredes da igreja católica local com pinturas de kachinas*. Ou como o Dr. Andrew Lakau, da província de Enga, nas Terras Altas da Nova Guiné, que apareceu paramentado em estilo tradicional para receber seu diploma de doutor em filosofia da Universidade de Queensland, em dezembro de 1994. A reportagem do jornal informa que ele preferira tal vestimenta à beca normalmente usada em tais cerimônias acadêmicas, "devido ao grande significado que a ocasião tinha para ele, sua família e sua cultura" (The Australian: 21/12/1994). Mas não serão justamente esses mestres do local e do global os que estão na melhor posição para atuar como mediadores entre os dois? É bem verdade que esse papel se presta à duplicidade e ao abuso de confiança; mas ele também sofre a atração gravitacional dos valores indígenas, uma vez que exprime o fenômeno - já discutido a propósito das sociedades transculturais - de obtenção de poder local através de objetos e experiências adquiridos em proezas que transcendem as fronteiras culturais.

Terence Turner invoca uma tradição kayapó desse tipo, em conexão com o papel de liderança desempenhado pelos indivíduos interculturalmente sofisticados. Historicamente, observa ele, "a chefia tem sido legiti-

\footnotetext{
* N.T. - Os kachina ou katchina são uma raça de divindades com um papel central na mitologia e na vida ritual dos Zuni e demais Pueblos do sudoeste dos Estados Unidos.
} 
mada pela demonstração de sua eficácia em ultrapassar os limites da comunidade aldeã e trazer do exterior, de fontes estrangeiras, recursos ou itens de valor". Nos vel hos tempos, isso podia significar ter de liderar longas excursões de caça, ou pilhar aldeias de outros índios e de brancos. M as com a "pacificação" nos anos 50 , a habilidade de extrair bens e concessões políticas dos brancos passou a encarnar tais virtudes sociais. Assim, os mediadores modernos de relações interétnicas tornaram-se os "equivalentes funcionais" dos guerreiros kayapó que aterrorizavam a região há cinqüenta anos (Turner 1995; cf. Barth 1969:33). De qualquer modo, as aparentes contradições entre aculturação e indigenização são freqüentemente neutral izadas pelas contradições de classe inerentes às culturas dominantes capitalistas - refiro-me às estruturas de discriminação e de exclusão das quais os movimentos culturais indígenas costumam extrair seus líderes e sua paixão.

A "volta às origens", como observou A milcar Cabral, é gerada como resposta às injustiças perpetradas pelos postos avançados coloniais da ordem mundial capitalista (Cabral 1973a; 1973b). M ártir do movimento de libertação de Guiné-Bissau, Cabral foi um dos primeiros a falar do papel da cultura na luta anticolonial. Segundo ele, a cultura entra de dois modos nessa luta. Em primeiro lugar, no "drama social e cultural" da população indígena que ascendeu às classes médias urbanas ou à elite colonial. Incapaz de transpor "as barreiras impostas pelo sistema", de se integrar verdadeiramente e de participar da ordem ocidental dominante, uma fração importante da burguesia indígena é marginalizada por seu próprio sucesso: "assim, ela se volta para o outro pólo do conflito social e cultural em que está envolvida - a massa do povo" (Cabral 1973a:15). Em segundo lugar e conseqüentemente, a luta do povo pela libertação é uma guerra cultural, pois aquilo que, precisamente, foi atacado pelo sistema de dominação estrangeira - pela economia capitalista e pela ideologia desenvolvimentista ocidental, pelas disciplinas dos impostos e taxas, do censo demográfico, do saneamento, da missionarização e outros meios de controle colonial -, aquilo que foi atacado é a própria forma de vida do povo. O colonialismo é um processo gigantesco de hegemonia cultural. Por isso a cultura, escreveu Cabral, "mostrou ser o fundamento mesmo do movimento de libertação" (1973a:16). E, ao restabelecer o controle do povo sobre sua própria existência, a luta pela libertação irá restaurar a historicidade de sua cultura. Como uma sociedade "que realmente consegue se libertar do jugo estrangeiro retoma os caminhos ascendentes de sua própria cultura, a luta pela libertação é acima de tudo um ato cultural" (Cabral 1973a). 
Esse sentido político do culturalismo continua hoje a ecoar, nesta assim chamada era pós-colonial, no discurso dos intelectuais africanos. 0 mesmo ocorre com a apreciação do futuro da tradição. Como diz Paulin Houtondji, "a cultura não é somente uma herança; é também um projeto" (1994). Ou ainda, na observação paralela de Elika M 'Bokolo, a cultura é uma exigência de formas de modernidade especificamente africanas:

“Por todo o século XX, a cultura tem sido o campo de batalha que os africanos escolheram para obter o reconhecimento de sua dignidade, o que envolve muito mais que o mero reconhecimento de seus direitos civis e políticos. Desde a independência, os mais legítimos porta-vozes do continente nunca deixaram de chamar a atenção para a cultura enquanto particularidade constitutiva da África contemporânea, seja para sublinhar que, no 'toma lá dá cá' mundial, é justamente a cultura que constitui a contribuição específica do continente, seja para exigir que o desenvolvimento se conforme às exigências da cultura africana" (1994).

O legado e o resultado de um colonialismo que via a si mesmo como missão civilizadora é que a luta política e a cultura, entre os povos outrora dominados, são alternadamente meio e fim uma para a outra. Recordemos as origens do conceito antropológico de cultura no contra-Iluminismo germânico: esse tipo de gemelaridade funcional não é coisa nova. Tampouco o movimento culturalista contemporâneo é menos genuíno por estar associado a um envolvimento prático. Nas palavras de Fredrik Barth, o fato de que "as formas contemporâneas sejam predominantemente políticas não Ihes retira seu caráter étnico. Tais movimentos políticos constituem novos modos de fazer com que as diferenças culturais sejam organizacionalmente relevantes" (1969:34).

Foi assim que os M aya da Guatemala estiveram engajados, durante praticamente toda a última década, na organização cultural de sua difícil situação (Warren 1992; Watanabe 1995). Na comunidade rural das Terras Altas estudada por Kay Warren, a famosa hierarquia civil-religiosa que aparentemente havia desmoronado no início dos anos 70 foi retomada, sob outra forma, em 1989 - precisamente pelo grupo da Ação Católica que a havia liquidado. A costumbre, que havia recentemente sido tão vilipendiada e rejeitada por muitos Maya, foi revitalizada como algo de valor inestimável. Como ocorreu nas ilhas do Pacífico e em muitas outras partes do mundo, a contradição entre o costume e a modernidade começa a se dissolver. Enquanto isso, nas cidades, J ohn Watanabe está documentando o desenvolvimento e a defesa de uma cultura pan-maya por 
parte de uma classe emergente de intelectuais e profissionais de formação universitária. Independentemente de seu sucesso no contexto nacional, esses M aya "não apenas escolheram manter sua identidade étnica, mas também lutam para que suas línguas, culturas e histórias sejam reconhecidas como temas válidos dentro da academia - e como dignos de respeito pela sociedade como um todo" (Watanabe 1995:31)26.

O culturalismo maya continua a se desenvolver, apesar das críticas feitas por intelectuais nacionais, tanto de esquerda como de direita. Para os marxistas, a "cultura maya" é uma falsa consciência da condição indígena, ou a mera roupagem ideológica de uma resistência popular ao colonialismo e à opressão de classes. Seja como for, o culturalismo maya, por sua particularização étnica, enfraquece a unidade geral da luta revolucionária do proletariado. Para os conservadores de direita, a ênfase na indianidade é uma vergonha para a nação e uma ameaça à sua integridade. Pouco importa, pois os intelectuais indígenas foram em frente e fundaram centros de estudos dedicados à promoção da língua e cultura maya, à descolonização da história maya e à pesquisa antropológica sobre suas próprias comunidades e tradições (Watanabe 1995:32-33).

Comentando a situação política análoga dos Tukano da Colômbia, J ean J ackson (1995) fez a observação mordaz de que tanto a esquerda como a direita advogam uma política cultural assimilacionista para os índios - que estes rejeitam ativamente. Tanto os teóricos da modernização como os marxistas gostariam de reduzir a especificidade histórica e a organicidade cultural das demandas indígenas a programas nacionais genéricos de desenvolvimento econômico ou de antiimperialismo americano. Mas o que os Tukano querem é sua própria cultura.

A significação histórica desse culturalismo do final do século $X X$ ainda não está completamente clara. Mas algumas dimensões de interesse antropológico já são visíveis. A primeira, e mais óbvia, é que a nova autoconsciência cultural dos povos indígenas é um aspecto da expansão global da ordem capitalista ocidental, sobretudo de seus modos mais recentes de colonização, mercantilização e comunicação. M as insisto: não se trata de uma reação inteiramente conservadora, uma volta a algum tipo de condição pré-européia primordial. Ao contrário, a volta às origens está acoplada a um desejo de manter e expandir o acesso às inovações técnicas, médicas e demais "benefícios" materiais do sistema mundial. Os Inuit não querem abrir mão de seus snowmobiles [trenós motorizados], nem os nativos de Fiji de seus motores de popa; mas querem utilizá-los para seus próprios fins, como, por exemplo, visitar os parentes. Eles querem englobar a ordem global em suas próprias ordens cosmológicas. 
À proporção que os povos locais vão, assim, criando espaços diferenciados dentro do ecúmeno, a estrutura planetária da cultura vai-se transformando (Hannerz 1992:217 e ss.). Estamos diante de uma nova organização mundial da cultura humana e de novos modos de produção histórica. No plano mundial, a humanidade, unificada pelos fluxos culturais globais que correm pelos canais da integração econômica, está começando a coincidir efetivamente com a espécie humana27. M as, ao mesmo tempo, ao se infletirem localmente, os fluxos globais diversificam-se de acordo com esquemas culturais particulares. "A gora existe uma cultura mundial, mas é preciso deixar bem claro o que isso significa. Essa cultura é marcada mais por uma organização da diversidade que por uma replicação da uniformidade" (Hannerz 1990:237). A nova organização planetária pode, portanto, ser descrita como a Cultura M undial da(s) cultura(s) [a World Culture of cultures].

Dada essa ordem estrutural, não há sentido em lamentar por "inautênticas" as formas de adaptação dos povos locais ao Sistema M undial, sequer quando eles se apropriam das imagens ocidentais do "nativo" como signos de sua própria alteridade - seja com propósitos aparentemente benignos (como quando os "nativos" utilizam, em benefício próprio, toda a sabedoria ecológica que o movimento ambientalista global Ihes imputa), seja com propósitos explicitamente comerciais (como na exploração do mercado turístico ávido de danças "nativas", artefatos ou coisa que valha). É assim que se faz hoje a história cultural, em um intercâmbio dialético do global com o local. Pois ficou bem claro agora que o imperialismo não está lidando com amadores nesse negócio de construção de alteridades ou de produção de identidades28.

O culturalismo é a formação discursiva moderna das identidades indígenas em sua relação com as alteridades global-imperiais. Como tal, ele envolve certos modos de produção histórica que os antropólogos já conhecem há muito tempo. Os "movimentos nativistas" são um dos itens da pauta antropológica há mais de cinqüenta anos. Em 1943, Ralph Linton definiu o nativismo como "qualquer tentativa consciente e organizada, por parte dos membros de uma sociedade, de reavivar ou perpetuar aspectos selecionados de sua cultura" (1943:220). O interessante é que o Renascimento europeu, com toda a sua reencenação expurgada e estilizada das tradições pagãs, encaixa-se perfeitamente nessa definição; ademais, ele levou a algo chamado "civilização moderna". Recordando novamente Linton: sabemos que estamos na moderna civilização norte-americana quando, após tomar seu café da manhã, um homem se recosta para ler seu jornal "impresso em caracteres inventados pelos antigos semitas, 
sobre um material inventado na China, por um processo inventado na Alemanha. Enquanto digere as notícias sobre os problemas estrangeiros, ele irá, se for um bom cidadão conservador, agradecer a uma divindade hebréia, em uma língua indo-européia, pela graça de ser 100\% americano" (Linton 1936:327). Igualmente, se os estudos pós-coloniais não parecem ter sido indispensáveis para que aprendêssemos algo sobre a hibridização ou a indigenização, tampouco devemos ver as formas populares atuais de tradicionalismo como meros produtos do imperialismo tardio. Estou falando da "inversão da tradição" tanto quanto da "invenção da tradição", e de outros tantos modos pelos quais as sociedades selecionam certos costumes como marcadores diacríticos e autodefinições de sua "cultura".

A inversão da tradição é um processo de autodefinição cultural por oposição complementar aos costumes dos povos com os quais é preciso se haver. Nicholas Thomas (1992a; 1992b) recorreu a essa expressão para descrever como os povos colonizados procuram se distinguir de seus senhores coloniais através da inversão das disposições habituais destes últimos: o modo como, por exemplo, os fijianos estabelecem um contraste, obviamente favorável a si mesmos, entre seu costume de partilhar bens e os hábitos econômicos dos brancos. Tratava-se, no caso, não apenas de uma negação inventada, mas de uma diferença bem real, diferença que os nativos de Fiji haviam percebido muito antes de os europeus fazerem dela uma questão colonial (Sahlins 1993; Thomas 1993). Gregory Bateson (1936) já havia atentado para fenômenos semelhantes, para aquilo que ele chamou de "cismogênese" nas relações interculturais. Certos exemplos dados por Bateson de especialização e interdependência ecológica das sociedades melanésias também indicavam que o processo podia ocorrer na ausência do colonialismo ocidental. Com efeito, Lévi-Strauss é do parecer que a oposição complementar é um princípio histórico geral de diversificação humana, como o testemunha o amplo papel que desempenha nas transformações estruturais descritas nos quatro volumes das M ythologiques. "M uitos costumes nasceram," escreveu ele em Raça e História, "não por alguma necessidade interna ou um acidente favorável qualquer, mas pela simples vontade de não se ficar para trás em relação a um grupo vizinho [...]. Conseqüentemente, a diversidade das culturas não deve nos conduzir a uma observação fragmentária ou fragmentadora. Ela é menos função do isolamento dos grupos humanos que das relações entre eles" (Lévi-Strauss 1952:17)29.

Algo semelhante pode-se concluir acerca da "invenção da tradição". Trata-se de uma venerável dinâmica de distinção cultural que está pas- 
sando por uma fase de grande sucesso histórico com os projetos do culturalismo indígena. A análise feita por Malinowski das lendas clânicas como cartas-patentes que legitimavam historicamente os interesses contemporâneos, o estudo de Evans-Pritchard sobre a historicidade genealogicamente manipulada dos sistemas de linhagens segmentares, e diversos outros que seguiram seus passos, tudo isso preparou os antropólogos para a atual conjuntura histórica. E aliás, não teria sido mesmo o vel ho Boas quem estabeleceu os fundamentos teóricos para uma compreensão do tradicionalismo discursivo, ao fazer suas famosas observações sobre a consciência das categorias culturais como uma elaboração secundária?

A relevância, para a presente discussão, desse argumento tantas vezes repetido, é mais ou menos a seguinte. Os "fenômenos etnológicos" são semelhantes às categorias lingüísticas, disse Boas, ao implicarem ambos uma ordenação da experiência e do comportamento segundo princípios normal mente inconscientes, e cujas razões de existência geralmente remontam a tempos imemoriais. Há, entretanto, uma diferença entre a língua e outros costumes, da qual se segue uma historicidade diferente:

"Parece que a diferença essencial entre os fenômenos lingüísticos e os demais fenômenos etnológicos é que as classificações lingüísticas nunca se tornam conscientes, ao passo que os outros fenômenos etnológicos, embora tenham a mesma origem predominantemente inconsciente, tornam-se com freqüência conscientes, gerando, assim, racionalizações secundárias e reinterpretações" (Boas 1966:63).

Os costumes tornam-se conscientes, quando mais não seja, por causa da própria possibilidade de sua violação - inclusive aquela ocasionada pelo exemplo de costumes contrastantes vigentes em povos vizinhos - , o que notadamente exige que eles sejam inculcados nos jovens, juntamente com os sentimentos morais e emocionais apropriados. Obrigada assim a encontrar explicações racionais para práticas cujas razões são desconhecidas, a consciência da cultura não é uma mera racionalização, mas uma quase-tradição consistente com os saberes, narrativas e interesses da sociedade (cf. Wagner 1975). Boas fornece alguns exemplos bastante eloqüentes extraídos de nossa própria experiência cultural, notando nossa inclinação a explicar tudo e qualquer coisa através de mitos de origem de tipo utilitarista. Assim, o tabu do incesto deve ter sido inventado com o intuito de evitar defeitos genéticos; ou ainda: comemos com garfo em vez de faca porque uma faca poderia cortar a boca - embora os antigos garfos de aço pudessem ser tão perigosos como uma faca (Boas 1938:207- 
208). Poderíamos acrescentar a essa lista a forte predisposição das ciências sociais norte-americanas para explicar tudo, toda sorte de costumes, os nossos como os dos outros povos, por suas vantagens econômicas. (Como dizia Hocart, o tema da utilidade domina o estudo da cultura porque domina a cultura que estuda.) Portanto, qualquer que seja a validade histórica de tais racionalizações, elas são funcional mente consistentes com a ordem histórica imanente. As elaborações secundárias conscientes permanecem sendo autênticas expressões culturais; elas articulam os meios organizacionais e os fins da sociedade. Para compreendermos os movimentos cultural istas contemporâneos, as lições da sabedoria boasiana tradicional poderiam ser tomadas da seguinte forma: a defesa da tradição implica alguma consciência; a consciência da tradição implica alguma invenção; a invenção da tradição implica alguma tradição.

A emergente antropologia da Cultura das culturas não precisa, portanto, esquecer as realizações de seus predecessores. Isto posto, a autoconsciência cultural decorrente da influência recíproca entre o M undo e a Aldeia vem assumindo uma variedade de formas originais. A penas na M elanésia, os estudos de Roger Keesing, Lamont Lindstrom, M argaret J olly, Robert Foster e outros revelaram uma série de movimentos de kastom: variações nos modos de continuidade histórica com o passado aborígine; diferenças nas práticas tradicionais às quais se associam de maneira seletiva valores nostálgicos e identidades étnicas; diferenças na organização social da defesa do ancien régime - notadamente os interesses diferenciais de homens e mulheres, de chefes e comuns, de diferentes gerações na retomada da tradição; diversidade das relações entre kastom, dinheiro, governo e cristianismo; variações na política antiocidentalista de pureza cultural; diferenças na tensão entre movimentos culturais nacionais, regionais e locais; e muito mais ${ }^{30}$. Em regra - há exceções e permutações - , o culturalismo tornou-se o discurso englobante do developman e das sociedades transculturais em evolução.

\section{Conclusão}

A interação de todos os modos de produção histórica aqui discutidos está produzindo uma explosão de formas culturais. Assim, enquanto disciplina, a antropologia parece estar tão bem de vida como sempre esteve: com as culturas desaparecendo enquanto ainda estávamos aprendendo a percebê-las, para reaparecer logo em seguida de maneiras que não havíamos previsto. 
Não obstante, para a antropologia, a novidade da atual organização da cultura fez-se acompanhar de uma ironia desoladora. Defrontando-se com uma Cultura M undial da(s) cultura(s), com um desenvolvimento que levou de roldão as velhas culturas da antropologia - os sistemas supostamente limitados, coerentes e sui generis de antanho - , a disciplina foi tomada de um pânico pós-moderno acerca da própria possibilidade do conceito de cultura. Exatamente quando os povos por el es estudados estavam a descobrir suas "culturas" e a proclamar o direito destas à existência, os antropólogos punham-se a debater a realidade e a inteligibilidade do fenômeno. Todos tinham uma cultura; só os antropólogos duvidavam disso. Mas a hipocondria epistemológica da disciplina parece ter sido causada por essa reorganização planetária da cultura, não por algum tipo de desordem inerente ao fenômeno - sobre a qual o conhecimento humano nada poderia dizer. Felizmente, parece que a filosofia não-existencialista está passando. A gora é explorar toda essa imensa variedade de processos culturais e de relações interessantes.

Aqui vai uma canção moderna dos Enga das Terras Altas da N ova Guiné:

Quando deles tiver me apossado,

Dos grandes livros das terras baixas,

Voltarei feliz, a passos largos,

Para Wabag, para a minha terra,

Por onde passam as estrelas serenas.

Essa é minha herança, a terra de meus orgulhosos antepassados,

É lá que farei minha casa,

E onde ficarei.

Ali viverei,

As estrelas passando sobre mim,

E eu com os livros seguros nas mãos.

(Talyaga 1975:Canção 21)

Tradução de Déborah Danowski

e Eduardo Viveiros de Castro
Recebido em 3 de fevereiro de 1997

A provado em 17 de fevereiro de 1997

M arshall Sahlins é professor (Charles F. Grey Distinguished Service Professor of Anthropology) da Universidade de Chicago. Entre seus livros mais conhecidos estão Stone Age Economics (1972), Culture and Practical Reason (1976), Historical M etaphors and M ythical Realities (1981), I slands of History (1985), e How “N atives” Think: A bout Captain Cook, for Example (1995). 


\section{Notas}

1 O texto dessa conferência foi lido pela primeira vez na Universidade do Havaí, em Hilo; em seguida, foi reescrito e lido no East-West Center de Honolulu, antes de ser novamente revisto e apresentado, algumas semanas depois, na Universidade do Pacífico Sul.

2 Nos países insulares analisados por Bertram e Watters (sobretudo Niue, o arquipélago de Cook, Tokelau, Kiribati e Tuvalu), as principais fontes de renda eram os salários do serviço público, seguidos pelas remessas dos migrantes e pela agricultura comercial. As duas primeiras eram de origem ultramarina - notadamente a ajuda externa que sustentava a pesada burocracia local - e a maior parte do dinheiro era destinada ao consumo corrente. Assim, não havia boas perspectivas de "desenvolvimento", mas, ao contrário, um sistema "permanentemente transicional" de dependência: um amálgama "incongruente" (para observadores de fora) de um setor al deão neotradicional, um setor público moderno e um setor comercial dominado pela importação. Dado o peso relativo da ajuda externa e da burocracia do serviço público, Watters fala de um "regime 'burocrático de atravessadores'" (1987:49).

$3 \mathrm{Na}$ "Nota do Editor" que introduz a reedição recente de Tales of the Tikongs, Vilisoni Hereniko chama a atenção para a impávida resistência popular ao maremoto desenvolvimentista que ameaça as ilhas: “Estas são menos histórias de um impacto fatal que contos otimistas sobre as respostas indígenas ao imperialismo cultural e econômico" (1983:vii).

4 Watters, um dos autores do conceito de MIRAB, reconheceu que as remessas de dinheiro dos migrantes expressavam "a natureza duradoura e bilateral da relação de reciprocidade" (1987:37).

5 Macpherson (1985:243) adverte-nos judiciosamente que os samoanos, na presença de europeus, mostram uma tendência a manter reservas acerca de sua própria sociedade, pois a contraparte disso, o entusiasmo pela terra natal - que não é uma disposição exclusivamente samoana - , é parte de uma idealização do que é a vida em casa e a vida no estrangeiro, tipicamente expressa pelo setor complementar (ver adiante).

6 É possível que formações interculturais similares tenham existido desde a Antiguidade, em cidades de Estados não-nacionais. Outros casos análogos seriam as comunidades dispersas de mercadores árabes e indianos estabelecidas na China e Indonésia no primeiro milênio de nossa era.

7 Ver, entre outros, Bonnemaison (1985); Bretell (1986); Bruner (1961); Chapman (1978); Prothero e Chapman (1985); Elkan (1985); Errington e Gewertz (1993); J ackson (1969); Garbett e Kapferer (1970); Gmelch (1980); Gugler (1969); Gugler 
e Flanagan (1978); Guillet e Uzzell (1976); Hart (1971); Hugo (1978; 1982; 1985); Kearney (1986); Lockwood, Harding e Wallace (1993); Lacey (1985); Lomnitz (1976); Lucardie (1985); M acpherson (1985); M acpherson, Shore e Franco (1978); M arcus (1981); M ayer (1961); Mitchell (1956); Parkin (1975a; 1975b); Provencher (1976); Roberts (1974); Ross e Weisner (1977); Rouse (1989); Trager (1988); Rumbiah (1985); Smith (1980); Uzzell (1979). Bartle (1981:109-110) afirma ter reunido mais de quatrocentas referências a tais ordens translocais publicadas apenas nos anos 60 e 70. Estou aqui, portanto, apenas evocando um fenômeno muito mais extenso e profundo.

8 Ao discutir os materiais de Sumatra, Bruner assim se contrapunha a Redfield: "Contrariamente ao que diz a teoria tradicional, o que vemos em muitas cidades asiáticas é que a sociedade não se seculariza, o indivíduo não se isola, as organizações de parentesco não se rompem, e tampouco as relações sociais no meio urbano se tornam impessoais, superficiais e utilitárias" (1961:508). Bruner prossegue mostrando não somente as similaridades entre os Batak da cidade e do campo, mas também as relações sistemáticas entre eles, inclusive do ponto de vista econômico.

9 Mitchell cita e critica D. F. M cCall sobre a urbanização africana: “'A formação das classes anuncia a morte do tribalismo no meio urbano. As marcas de classe são independentes do fato de se pertencer a uma tribo; as classes incluem pessoas de diversas tribos'" (M itchell 1956:15). Entre outras objeções, Mitchell observa que as posições de classe e o status tribal mantêm certa correspondência em virtude de tendências ocupacionais; ele observa ainda que tanto as identidades tribais como as de classe são situacionais, e não corporativas ou totais. M as "o essencial é que os africanos como um todo perfazem uma classe política, e os europeus uma outra" (M itchell 1956:17). J untamente com suas observações sobre a imitação das modas e maneiras européias enquanto marcas de "civilização", o célebre trabalho de Mitchell acerca da dança kalela constitui um bom complemento à análise de Amilcar Cabral sobre a dinâmica de classe e a "volta às origens" (ver adiante).

${ }^{10}$ A ssim, na África Ocidental, “era impossível negar a enorme relevância desses dados: sem exceção, eles mostram que os imigrantes nas mais diversas situações urbanas mantêm laços bastante fortes com sua área de origem, com aquilo que consideram sua 'casa'" (Gugler e Flanagan 1978:67).

11 Pace Gluckman: “Gluckman considerava mais produtivo ver a cidade e o campo como analiticamente distintos. Assim, duas explicações teoricamente diferentes do comportamento podiam ser desenvolvidas: uma apropriada à vida rural e a outra apropriada à vida urbana. $\mathrm{O}$ que estamos sugerindo é que a teoria social deve dar conta do comportamento em ambas as situações ao mesmo tempo, em parte porque os próprios imigrantes vêem seu comportamento nos dois cenários 
como interdependentes, e em parte porque os padrões da interação e dos laços psicológicos entre as duas áreas são fatores importantes que explicam as variações de atitude e comportamento por toda a África atual" (Ross e Weisner 1977:370-371).

12 Além dos estudos citados por M itchell, que, buscando transcender a dicotomia corrente, empregavam descrições como a de M ayer sobre os “conjuntos de relações" entre a cidade e o campo, ver também os autores citados acima, na nota 7. As formas mais recentes, pós-coloniais, são conceituadas por expressões como "transnacionalismo" ou "sistemas socioculturais transnacionais" (cf. Basch, Schiller e Blanc s/d; Sutton 1987). As “ethnoscapes" de Appadurai referem-se, em parte, ao mesmo fenômeno, embora o autor enfatize a desterritorialização como algo distinto das ordens centradas na terra natal aqui descritas (Appadurai 1991).

13 De maneira semelhante, Caroline Bretell afirma que, no noroeste de Portugal, a migração circular "realmente serviu para perpetuar um modo de vida" (1986:263).

14 Falando das comunidades ampliadas estabelecidas pela migração circular no Peru, Roberts fornece uma descrição característica das complementaridades geradas entre a cidade e as províncias: “Para encontrar ou criar empregos na cidade, para conseguir moradia ou assegurar outras formas de assistência, os migrantes utilizam-se dos parentes e conterrâneos previamente estabelecidos, ou com alguma experiência de trabalho na cidade. Os migrantes recebem produtos agrícolas das aldeias para fazer frente ao alto custo dos alimentos na cidade. Parentes mais velhos e outros dependentes [dos migrantes] são assistidos por meio de arranjos sociais e econômicos próprios da al deia. Desse modo, a organização aldeã permanece importante para o modo como os migrantes lidam com seu ambiente. De maneira semelhante, as aldeias continuam sendo organizadas com base na expectativa de que os migrantes financiarão cerimônias e outros projetos coletivos, fornecerão bens de consumo produzidos na cidade, ou servirão como parceiros essenciais em empreendimentos econômicos [rurais]" (1974:218).

15 Isso sem mencionar que, se acreditarmos no que diz Benedict Anderson (1983) sobre a formação das nações modernas, a espacialidade e a afiliação imaginária dificilmente serão mutuamente excludentes. Entretanto, seguir Anderson tem se mostrado problemático para muitos antropólogos, que já sabem há muito tempo que grupos sociais de todos os tipos - incluindo os assim chamados grupos face a face, para não falar das linhagens, clãs, tribos, províncias ou cidades são simbolicamente constituídos e, nesse sentido, "imaginários." Como Sartre disse em algum lugar, a cidade está presente em cada uma de suas ruas, sob a condição de estar sempre alhures.

16 Quero com isso incluir, e não ignorar, situações como a dos Red Xhosa, onde a pauperização do campo tem cada vez mais feito da migração circular um imperativo material categórico para a manutenção da ordem rural (cf. M ayer 1980; McAllister 1980). 
17 As remessas de dinheiro para as comunidades natais fornecem vários bons exemplos das diferenças entre desenvolvimento e developman, pois como obviamente intensificam as relações locais, promovendo assim o developman, elas são, caracteristicamente, consideradas irrelevantes para o desenvolvimento por sua natureza "social", em oposição a uma natureza "produtiva". Daí uma discussão recente sobre as remessas de dinheiro de J ayapuru, em Irian O cidental, para a comunidade natal da ilha de Nimbor: "Poucas remessas contribuíram para o desenvolvimento da aldeia ou para o crescimento econômico rural; a maioria foi dirigida para o estabelecimento ou a preservação da interdependência a longo prazo para com parentes e outras pessoas, aumentando o prestígio social por funcionarem como símbolos de reciprocidade, auto-respeito e identidade, e por constituírem uma forma de pagamento de dívidas sociais" (Rumbiah 1985:219).

18 Os Xhosa encenavam rituais de despedida e de boas-vindas para os migrantes, identificando suas viagens a feitos guerreiros (M CAllister 1980:213, $215,219)$. As músicas cantadas pelos Lesotho enquanto cruzavam a fronteira com a África do Sul tinham o mesmo significado (M oodie 1994:56).

19 Bonnemaison formulou o mesmo argumento a partir de seu trabalho etnográfico em Vanuatu. Para ele, a migração circular é em grande medida moldada pela "estrutura tradicional de mobilidade." "Uma viagem melanésia", diz ele, "era vivida na sociedade tradicional como uma odisséia cultural, associada à liberdade, ao encontro com o desconhecido, a novas experiências, à criatividade e outros valores positivos" (1985:62).

20 Já vimos algo da idealização da terra natal nos depoimentos dos samoanos de ultramar. Macpherson assim se exprime a respeito das visões da ilha natal correntes entre os samoanos da Nova Zelândia: “A cultura popular tem uma opinião muito positiva sobre Samoa Ocidental. Os músicos compõem e tocam canções que expressam um grande apego a Samoa e à sua cultura, um desejo de retornar à terra natal e a seus antigos amores. Em contextos mais formais, essas canções são pontilhadas de referências à 'nossa cultura venerada' (lo tatou aganu'u), à ‘nossa amada nação' (lo tatou atunu'u pele) e à superioridade moral do 'modo de vida samoano' (fa'a Samoa) - o que, por sua vez, se baseia na afirmação de que 'Samoa está fundada em Deus' (Ua Fa'avae ile A tua Samoa). Os que estão voltando por um tempo a Samoa se consolam com a perspectiva de se reunirem a seus entes queridos; de estarem em breve livres da obrigação de acordar cedo todo dia para um trabalho enfadonho nas fábricas controladas por supervisores palagi (europeus); de não mais estarem sujeitos aos infindáveis resfriados e gripes; e de estarem prestes a obter abrigo do clima geralmente pouco hospitaleiro prevalecente na sociedade anfitriã" (Macpherson 1985:247). Para uma observação complementar, porém menos lisonjeira, feita do ponto de vista da aldeia, ver O'Meara (1993).

21 Uma elevada proporção de membros do povo Luo está presente nas associações de trabalhadores de Nairobi; muitos Luo trazem as esposas e os filhos para morar consigo na cidade, pelo menos durante parte do ano; muitos deles têm inte- 
resses econômicos significativos na cidade. Refletindo sobre esses e outros índices de adaptação bem-sucedida dos Luo à vida urbana, Parkin observa: “ M as não há evidências de que esse intenso envolvimento social e econômico dos Luo em N airobi esteja acarretando uma diminuição das relações e interesses próprios ao meio rural. De fato, como Ross notou acerca de uma outra área de Nairobi, os moradores da cidade com um status mais alto e uma posição mais segura são, entre todos os grupos, os que têm maiores probabilidades de estar envolvidos com o meio rural. Podem ter comprado mais terras agrícolas, construído uma casa [...] e até ter expandido seus interesses abrindo um 'negócio' no campo, como uma loja ou um serviço de transportes. Fica claro, como seria de se esperar, que os mais bem-sucedidos na cidade têm uma maior probabilidade de explorar as novas oportunidades econômicas disponíveis em suas áreas de origem. Este fenômeno é tão familiar na África moderna que não precisamos nos demorar sobre ele" (Parkin 1975b:148).

22 Falando a partir de sua experiência em Santa Isabel, e notadamente a partir da observação das continuidades no desenvolvimento (ou developman) da chefia através dos períodos colonial e pós-colonial, Geoffrey White chegou a conclusões muito semelhantes acerca das "surpresas" dessa história. "Talvez uma das razões", escreve ele, "pelas quais a curta história pós-colonial dos novos Estados melanésios produziu tantas surpresas para os observadores estrangeiros tenha sido a incapacidade de antecipar a força potencial da cultura local como um meio de redefinição dos futuros políticos" (1992:101).

${ }^{23}$ Assim, em 1979, Turner criticava a tendência a se interpretar o destino de todos os povos indígenas a partir de casos extremos de desmoralização; isso exprimiria um fracasso "em dar aos povos que são objeto de sua preocupação a atenção e o respeito exigidos pela tenacidade e capacidade de luta que eles demonstram". Turner falava do "terrível e sedutor abuso de termos e temas como "genocídio' e 'etnocídio', que, no momento mesmo em que denunciam a absoluta desumanização dos seres humanos, tornam desnecessário dar conta positivamente da humanidade (isto é, das identidades socioculturais particulares, e das capacidades concomitantes de ação e adaptação social, política e cultural) das vítimas" (1979:4, 5).

24 Um movimento semelhante de resistência cultural conduzido em dois flancos pode ser visto nas recentes atividades dos Wánai, um pequeno grupo de língua caribe do médio Orinoco (Scaramelli 1996). Em junho de 1992, mais de quatrocentos anos após terem sido contatados pelos exploradores europeus, os homens Wánai se pintaram com os desenhos de guerra de seus ancestrais, preparando um ataque surpresa contra um poderoso povo vizinho, os Wóthuha [N.T. também conhecidos como Piaroa]. Como estratégia paralela, os Wánai escreveram à agência do governo venezuelano encarregada de resolver disputas legais entre os índios, denunciando os Wóthuha por terem invadido parte de suas terras - a mesma razão que os tinha posto em pé de guerra. Note-se que, no mesmo ano, a Revista Española de Antropologia A mericana publicava um artigo intitulado "Os Últimos Wánai", anunciando a "extinção cultural" desse povo. 
25 Terence Turner (1995) descreveu um conflito de gerações recente e mais complexo em certas comunidades kayapó. Aqui, uma geração mais jovem de gente do povo [commoners], juntamente com alguns anciãos com estatuto de chefe, usurpou os poderes dos évolués mais instruídos que anteriormente haviam intermediado as relações com a sociedade brasileira - mas em grande parte para benefício próprio. Turner chama a atenção para a continuidade desse fenômeno de solidariedade entre gerações alternadas (chefes e jovens sem poder) com as relações de parentesco tradicionais dos Kayapó.

26 Sobre o desenvolvimento análogo do culturalismo mixteca que se desenvolve na fronteira entre M éxico e Estados Unidos, mas que recorre à herança cultural da terra de origem no M éxico meridional, ver Kearney (1986:355).

27 A ppadurai (1991) definiu uma variedade de tipos ou dimensões de "fluxos culturais globais." Esse nível da ordem planetária não foi objeto de uma consideração detalhada pelo presente artigo, mas é certamente um dos temas centrais da nova antropologia.

28 Não devemos esquecer o processo que Kroeber (1948) chamou originalmente de "aculturação antagonística" ou, para usarmos chavões mais recentes, os usos da "mimesis" no controle da "alteridade" e na apropriação de seus poderes.

29 “Quando tiveres entrado na terra que o Senhor, teu Deus, te há de dar, não te porás a imitar as práticas abomináveis da gente daquela terra. Não se ache no meio de ti quem faça passar pelo fogo seu filho ou sua filha, nem quem se dê à adivinhação, à astrologia, aos agouros, ao fetichismo, à magia, ao espiritismo ou à evocação dos mortos, porque o Senhor, teu Deus, abominaria aqueles que se dão a essas práticas, e é por causa dessas abominações que o Senhor, teu Deus, expulsa diante de ti essas nações" (Deut., 18:9-12).

30 Ver, entre outros, Lindstrom (1982); Keesing (1982); N eumann (1992); White (1992); Babadzan (1985; 1988); Foster (1992) e vários artigos em M ankind, vol. 13, 1982. 


\section{Referências bibliográficas}

ANDERSON, Benedict. 1983. I magined Communities: Reflections on the Origin and Spread of Nationalism. London: Verso Editions/NLB.

APPADURAI, Arjun. 1991. “Global Ethnoscapes: Notes and Queries for a Transnational Anthropology". In: R. G. Fox (org.), Recapturing A nthropology. Santa Fe: School of American Research Press. pp. 191-210.

ASHM ORE, Malcolm, EDWARDS, Derek e POTTER, J onathan. 1994. “The bottom Line: The Rhetoric of Reality Demonstrations". Configurations, 2:1-14.

BABADZAN, Alain. 1985. "Tradition et Histoire: Quelques Problèmes de Méthode". Cahiers ORSTOM, Série Sciences Humaines, 21:115-123.

. 1988. "Kastom and Nation-Building in the South Pacific". In: R. Guidieri, F. Pellizi e S. J. Tambiah (eds.), Ethnicities and Nations. Austin: The Rothko Chapel. pp. 199-228.

BARTH, Fredrik. 1969. "Introduction”. In: Ethnic Groups and Boundaries. Bergen-Oslo: Universitets Forlaget. pp. 9-38.

BARTLE, Philip F. W. 1981. “Cyclical Migration and the Extended Community: A West African Example". In: R. B. Mandal (ed.), Frontiers in Migration Analysis. New Delhi: Concept Publishing Company. pp. 107-139.

BASCH, Linda, SCHILLER, Nina G. e BLANC, Cristina S. s|d. Nations Unbound: Transnational Projects, Postcolonial Predicaments, and Deterritorialized Nation-States. Australia: Gordon and Breach.

BATESON, Gregory. 1936. "Culture Contact and Schismogenesis". Man (n.s.), 35:178-183.
BERTRAM, I. G. e WATTERS, R. F. 1986. "The Mirab Process: Earlier Analyses in Context". Pacific Viewpoint, 27:47-59.

BOAS, Franz. 1938. The M ind of Primitive $M$ an. N ew York: The Free Press. . 1966. Introduction to Handbook of A merican Indian Languages (editado por P. Holder). Lincoln: University of Nebraska Press.

BONNEMAISON, J oel. 1985. “The Tree and the Canoe: Roots and Mobility in Vanuatu Societies". In: M. Chapman (ed.), M odernity and Identity in the Island Pacific. Pacific Viewpoint (Special issue), 26(1):30-62.

BRETELL, Caroline B. 1986. Men who Migrate, Women who Wait: Population and History in a Portuguese Parish. Princeton: Princeton University Press.

BRUNER, Edward M. 1959. “Kinship Organization among the Urban Batak of Sumatra". Transactions of the New York Academy of Sciences, 22:118-125.

. 1961. "Urbanization and Ethnic Identity in North Sumatra". American Anthropologist, 63:508-521.

CABRAL, A milcar. 1973a. "The Role of Culture in the Battle for Independence". UNESCO Courier, novembro. pp. 12-20.

.1973b. Return to the Source: Selected Speeches by Amilcar Cabral. New York: Monthly Review Press.

CHAPMAN, Murray. 1978. "On the Cross-Cultural Study of Circulation". International Migration Review, 12:559-569.

e PROTHERO, R. Mansell. 1985. "Themes on Circulation in the Third World". In: R. M. Prothero e M. 
Chapman (eds.), Circulation in Third World Countries. London: Routledge \& Kegan Paul. pp. 1-26.

ELKAN, Walter. 1985. “Is a Proletariat Emerging in Nairobi?". In: R. M. Prothero e M. Chapman (eds.), Circulation in Third World Countries. London: Routledge \& Kegan Paul. pp. 367-379.

EPSTEIN, A. L. 1958. Politics in an Urban Community. Manchester: Manchester University Press on Behalf of the Rhodes-Livingstone Institute.

ERRINGTON, Frederick e GEWERTZ, Deborah. 1993. "The Historical Course of True Love in the Sepik". In: V. S. Lockwood, T. G. Harding e B. J. Wallace (eds.), Contemporary Pacific Societies: Studies in Development and Change. Englewood Cliffs, N. J .: Prentice-Hall. pp. 233-248.

FOSTER, Robert. 1992. “Commoditization and the Emergence of Kastam as a Cultural Category: A New Ireland Case in Comparative Perspective". Oceania, 62:284-294.

GARBETT, G. K. e KAPFERER, B. 1970. "Theoretical Orientations in the Study of Labour Migration". The New Atlantis, 1(2):179-197.

GIFFORD, Edward W. 1929. Tongan Society. Bernice P. Bishop Museum, Bulletin no 61. Honolulu: Bishop Museum.

GLUCKMAN, Max. 1960. "Tribalism in Modern British Central Africa". Cahiers d'Études, 1:55-70.

GMELCH, George. 1980. "Return Migration". Annual Review of Anthropology, 9:135-159.

GUGLER, J osef. 1969. “On the Theory of Rural-Urban Migration: The Case of Subsaharan Africa". In: J . J ackson (ed.), Migration. Sociological Studies 2. Cambridge: Cambridge University Press. pp. 134-135. e FLANAGAN, William G. 1978. “Urban-Rural Ties in West Africa: Extent, Interpretation, Prospects, and Implications". African Perspectives, 1:67-78.

GUILLET, David e UZZELL, Douglas. 1976. "Introduction". In: D. Guillet e D. Uzzell (eds.), New Approaches to the Study of M igration. Houston: Rice University Press. pp. 1-23.

GULLIVER, P. H. 1957. “N yakusa Labour Migration". The Rhodes-Livingstone J ournal, 21:32-63.

GUPTA, Akhil e FERGUSON, J ames. 1992. “Beyond 'Culture': Space, Identity, and the Politics of Difference". Cultural Anthropology, 7:6-23.

HANNERZ, Ulf. 1990. “Cosmopolitans and Locals in World Culture". In: M. Featherstone (ed.), Global Culture. London: Sage Publications. pp. 237251.

1992. Cultural Complexity: Studies in the Social Organization of Meaning. New York: Columbia University Press.

HART, Keith. 1971. "Migration and Tribal Identity among the Frafras of Ghana". Journal of African and Asians Studies, 6:21-36.

HAU'OFA, Epeli. 1979. Corned Beef and Tapioca: Food Distribution Systems in Tonga. Canberra: Development Studies Center, Australian National University. . 1983. Tales of the Tikongs. Honolulu: University of Hawaii Press. . 1986. The Implications of Being Very Small. Paper delivered to the Tokai University/Friedrich Ebert- 
Stiftung Seminar on Cooperation in Development. Tokyo, novembro. . 1993. "Our Sea of Islands". In. E. Waddell, V. Naidu e E. Hau'ofa (eds.), A New Oceania: Rediscovering Our Sea of I slands. Suva: School of Social and Economic Development, University of the South Pacific/ Book House. pp 2-19.

HERENIKO, Vilisoni. 1983. “Editor's Note". In: E. Hau'ofa, Tales of the Tikongs. Honolulu: University of Hawaii Press. pp. vii-viii.

HOUTONDJ I, Paul. 1994. Culture and Development in Africa: Lifestyles, Modes of Thought and Forms of Social Organization. World Commission on Culture and Development. UNESCO, CCD-IV/94/REG/INF.9.

HUGO, Graeme J . 1978. Population M obility in West Java. Yogyakarta: Gadjah Mada University Press.

. 1982. "Circular Migration in Indonesia". Population and Development Review, 6:59-84.

. 1985. "Circulation in West J ava, Indonesia". In: R. M. Prothero e M. Chapman (eds.), Circulation in Third World Countries. London: Routledge \& Kegan Paul. pp. 75-99.

J ACKSON, J . (ed.). 1969. Migration. Sociological Studies 2. Cambridge: Cambridge University Press.

JACKSON, J ean. 1995. "Culture Genuine and Spurious: The Politics of Indianess in the Vaupés, Columbia". American Ethnologist, 22:3-27. J ANES, Craig R. 1990. Migration, Social Change, and Health: A Samoan Community in Urban California. Stanford: Stanford University Press.

J OLLY, M argaret. 1992. "Custom and the Way of the Land: Past and Present in Vanuatu and Fiji". Oceania, 62:330-354.

KEARNEY, M ichael. 1986. "From the Invisible Hand to the Visible Feet: An- thropological Studies of M igration and Development". Annual Review of Anthropology, 15:331-361.

KEESING, Roger M. 1982. "Kastom and Anticolonialism on Malaita: 'Culture' as a Political Symbol”. M ankind, 13:357-372.

KOTCHEK, Lydia. 1978. “Migrant Samoan Churches: Adaptation, Preservation, and Division". In: C. Macpherson, B. Shore e R. Franco (eds.), New Neighbors: I slanders in Adaptation. Santa Cruz: Center for South Pacific Studies, University of California, Santa Cruz. pp. 11-15.

KROEBER, Alfred. 1948. Anthropology. New York: Harcourt, Brace.

LACEY, Roderic. 1985. “J ourneys and transformations: The Process of Innovation in Papua New Guinea". In: M. Chapman (ed.), M odernity and Identity in the Island Pacific. Pacific Viewpoint (Special issue), 26(1):81-105.

LÉVI-STRAUSS, Claude. 1952. Race and History. Paris: UNESCO.

LINDSTROM, Lamont. 1982. “Leftamap Kastom: The Political History of Tradition on Tauna, Vanuatu". Mankind, 13:316-329.

LINTON, Ralph. 1936. The Study of Man. New York: D. Appleton-Century.

.1943. "Nativistic Movements". A merican Anthropologist, 45:230240.

LOCKWOOD, Victoria S., HARDING, Thomas G. e WALLACE, Ben J . (eds.). 1993. Contemporary Pacific Societies: Studies in Development and Change. Englewood Cliffs, N. J.: Prentice-Hall.

LOM NITZ, Larissa. 1976. “An Ecological Model for M igration Studies". In: D. Guillet e D. Uzzell (eds.), New Approaches to the Study of Migration. Houston: Rice University Press. pp. 131-146.

LUCARDIE, Ronald. 1985. “Spontaneous 
and Planned M ovements among the Makianese of Eastern Indonesia". In: M. Chapman (ed.), Modernity and Identity in the Island Pacific. Pacific Viewpoint (Special issue), 26(1):63-78.

MACPHERSON, Cluny. 1978. "Samoan Migration to New Zealand". In: C. Macpherson, B. Shore e R. Franco (eds.), New Neighbors: Islanders in Adaptation. Santa Cruz: Center for South Pacific Studies, University of California, Santa Cruz.

. 1985. "Public and Private Views if Home: Will Western Samoan Migrants Return?". In: M. Chapman (ed.), M odernity and Identity in the Island Pacific. Pacific Viewpoint (Special issue), 26(1):242-262.

, SHORE, Bradd e FRANCO, Robert (eds.). 1978. New Neighbors: Islanders in Adaptation. Santa Cruz: Center for South Pacific Studies, University of California, Santa Cruz. MARCUS, George E. 1981. "Power on the Extreme Periphery: The Perspective of Tongan Elites in the Modern World System". Pacific Viewpoint, 22:48-64.

.1993. “Tonga's Contemporary Globalizing Strategies: Trading in Sovereignty amidst International Migration". In: V. S. Lockwood, T. G. Harding e B. J. Wallace (eds.), Contemporary Pacific Societies: Studies in Development and Change. Englewood Cliffs, N. J .: PrenticeHall. pp. 21-33.

MAYER, Philip. 1961. Townsmen or Tribesmen: Conservatism and the Process of Urbanization in a South African City. Cape Town: Oxford University Press.

. 1962. "M igrancy and the Study of Africans in Towns". American Anthropologist, 64:576-592.

. 1980. “The Origin and Decline of
Two Rural Resistance Ideologies". In: P. Mayer (ed.), Black Villages in an Industrial Society: Anthropological Perspectives on Labour Migration in South Africa. Cape Town: Oxford University Press. pp. 1-80.

M'BOKOLO, Elika. 1994. Culture and Development in Africa. World Commission on Culture and Development. UNESCO, CCD-IV/94/REG/ INF.3.

MCALLISTER, P. A. 1980. “Work, Homestead and the Shades: The Ritual Interpretation of Labour Migration among Gcaleka". In: P. Mayer (ed.), Black Villages in an Industrial Society: Anthropological Perspectives on Labour Migration in South Africa. Cape Town: Oxford University Press. pp. 205-253.

MCCALL, Grant. 1994. Rapanui: Tradition and Survival on Easter Island (2a ed.). St. Leonards, Australia: Allen \& Unwin.

MITCHELL, J . Clyde. 1956. “Urbanization, Detribalization and Stabilization in Southern Africa: A Problem of Definition and Measurement". In: Urbanization in Africa South of the Sahara. London: UNESCO. pp. 693-711. . 1967. "Theoretical Orientations in African Urban Studies". In: M. Benton (ed.), The Social Anthropology of Complex Societies. ASA Monograph. London: Tavistock. pp. 37-68. MOODIE, T. Dunbar. 1994. Going for Gold. Berkeley: University of California Press.

NEUMANN, Klaus. 1992. “Tradition and Identity in Papua New Guinea: Some Observations Regarding Tami and Tolai". Oceania, 62:295-316.

O'MEARA, Tim. 1993. "The Cult of Custom M eets the Search for M oney in Western Samoa". In: V. S. Lockwood, T. G. Harding e B. J. Wallace (eds.), Contemporary Pacific Societies: Studies in Development and 
Change. Englewood Cliffs, N. J .: Prentice-Hall. pp. 135-155.

PARKIN, David (ed.). 1975a. Town and

Country in Central and Eastern Africa. London: Oxford University Press for the International African Institute.

. 1975b. “M igration, Settlement and the Politics of Unemployment: A Nairobi Case Study". In: D. Parkin (ed.), Town and Country in Central and Eastern Africa. London: Oxford University Press for the International African Institute. pp. 145-155.

PEARSON, David. 1994. "Self-Determination and Indigenous Peoples in Comparative Perspective: Problems and Possibilities". Pacific Viewpoint, 35(2):129-142.

PROTHERO, R. Mansell e CHAPMAN, Murray (eds.). 1985. Circulation in Third World Countries. London: Routledge \& Kegan Paul.

PROVENCHER, Ronald. 1976. “Shifts in the Cycle of Experience: M alay Perceptions of M igration". In: D. Guillet e D. Uzzell (eds.), New Approaches to the Study of M igration. Houston: Rice University Press. pp. 63-71.

ROBERTS, Bryan. 1974. “The Interrelationships of City Provinces in Peru and Guatemala". Latin American Urban Research, 4:207-235.

ROSS, Marc Howard e WEISNER, Thomas. 1977. “The Rural-Urban Migrant Network in Kenya: Some General Implications". American Ethnologist, 4:359-375.

ROUSE, Roger. 1989. Mexican Migration to the United States: Family Relations in the Development of a Transnational Migration Circuit. Ph.D. Dissertation in Anthropology, Stanford University.

RUMBIAH, Michael. 1985. “N imboran Migration to J ayapura, West Irian". In: M. Chapman (ed.), Modernity and Identity in the Island Pacific. Pacific Viewpoint (Special issue), 26(1):206-220.

RYAN, Dawn. 1989. “Home Ties in Town: Toaripi in Port Moresby". Canberra Anthropology, 12:19-22.

1993. “Migration, Urbanization and Rural-Urban Links: Toaripi in Port Moresby". In: V. S. Lockwood, T. G. Harding e B. J . Wallace (eds.), Contemporary Pacific Societies: Studies in Development and Change. Englewood Cliffs, N. J .: PrenticeHall. pp. 219-232.

SAHLINS, M arshall. 1993. "Cery Cery Fuckabede". A merican Ethnologist, 20:848-867.

SALISBURY, Richard F. e SALISBURY, Mary E. 1972. "The Rural-Oriented Strategy of Urban Adaptation: Siane Migrants in Port Moresby". In: R. Weaver e D. White (eds.), The Anthropology of Urban Environments. Boulder, Co.: The Society for Applied Anthropology. pp. 59-68.

SCARAM ELLI, Frank. 1996. Course Paper. Anthropology 302. University of Chicago.

SMITH, G. A. 1980. “Huasicanchino Livelihoods: A Study of Extended Domestic Enterprises in Rural and Urban Peru". Canadian Review of Sociology and Anthropology, 17:357-366.

SUTTER, Frederic Koeler. 1989. The Samoans: A Global Family. Honolulu: University of Hawaii Press.

SUTTON, Constance. 1987. "The Caribbeanization of N ew York and the Emergence of a Transnational Socio-Cultural System". In: C. Sutton e E. Chaney (eds.), Caribbean Life in New York City: Sociocultural Dimensions. New York: Center for Migration Studies. pp. 15-30.

TALYAGA, K. 1975. M odern Enga Songs. Boroko: Institute of Papua $\mathrm{New}$ Guinea Studies. 
THOMAS, Nicholas. 1992a. "The Inversion of Tradition". American Ethnologist, 19(2):213-233.

.1992b. "Substantivization and Anthropological Discourse". In: J. G. Carrier (ed.), History and Tradition in Melanesian Anthropology. Berkeley: University of California Press. pp. 64-85.

. 1993. "Beggers Can Be Choosers". American Ethnologist, 20(4):868-876.

TRAGER, Lilian. 1988. The City Connection: Migration and Family Interdependence in the Philippines. Ann Arbor: The University of Michigan Press.

TURNER, Terence. 1979. “A nthropology and the Politics of Indigenous Peoples' Struggles". Cambridge Anthropology, 5(1):1-43.

. 1986. M anuscrito inédito.

. 1987. "The Politics of Culture". In:

B. Spooner (ed.), Conservation and Survival. Oxford: Oxford University Press.

. 1991. “Representing, Resisting, Rethinking: Historical Transformations of Kayapo Culture and Anthropological Consciousness". In: G. Stocking (ed.), Colonial Situations: Essays on the Contextualization of Ethnographic Knowledge. M adison: The University of Wisconsin Press. pp. 285-313.

.1992. "Defiant Images: The Kayapo Appropriation of Video". Anthropology Today, 8(6):5-16. . 1993. "From Cosmology to Ideology: Resistance, Adaptation and Social Consciousness among the Kayapo". South American Indian Studies, 2:1-13.

.1995. The Kayapo Revolt Against Extractivism: An Indigenous People's Struggle for Socially Equitable and Ecologically Sustainable Production. Manuscrito.

UZZELL, Douglas. 1979. “Conceptual
Fallacies in the Rural-Urban Dichotomy". Urban Anthropology, 8:333-350.

VAN VELSEN, J . 1960. “Labor M igration as a Positive Factor in the Continuity of Tonga Tribal Society". Economic Development and Cultural Change, 8:265-278.

WADDELL, Eric, NAIDU, Vijay e HAU'OFA, Epeli. 1993. A N ew Oceania: Rediscovering Our Sea of Islands. Suva: School of Social and Economic Development, University of the South Pacific/Book House.

WAGNER, Roy. 1975. The Invention of Tradition. Englewood Cliffs, N. J .: Prentice-Hall.

WARREN, Kay B. 1992. “Transforming Memories and Histories: The Meanings of Ethnic Resurgence for M ayan Indians". In: A. Stepan (ed.), Americas: New Interpretative Essays. New York: Oxford University Press. pp. 189-219.

WATANABE, J ohn M. 1995. “Unimagining the Maya: Anthropologists, Others, and the Inescapable Hubris of Authorship". Bulletin of Latin American Research, 14:25-45.

WATTERS, Ray. 1987. “Mirab Societies and Bureaucratic Elites". In: A. Hooper et alii (eds.), Class and Culture in the South Pacific. Suva: Center for Pacific Studies, University of Auckland/Institute of Pacific Studies, University of the South Pacific. pp. 32-54.

WHITE, Geoffrey M. 1992. “The Discourse of Chiefs: Notes on a M elanesian Society". Contemporary Pacific, 4:73-108.

WHITEFORD, Linda. 1979. "The BorderIand as an Extended Community". In: F. Cámara e R. V. Kemper (eds.), $M$ igration Across Frontiers. Albany: State University of New York. pp. 127-137. 


\section{Resumo}

Este artigo (publicado em duas partes) examina e refuta as críticas ao conceito de cultura. A identificação pós-modernista da "cultura" com o colonialismo e o imperialismo é um diagnóstico falso: o contexto histórico-ideológico de gestação da idéia de cultura, marcado pela reação ao universalismo iluminista, aponta na direção oposta. Por sua vez, as ansiedades sobre o fim iminente da variedade cultural humana se mostram sem objeto: a globalização e outras peripécias capitalistas, longe de impor uma hegemonia monótona sobre o planeta, têm gerado uma diversidade de formas e conteúdos culturais historicamente sem precedentes.
Abstract

This article (published in two parts) examines and refutes critiques of the concept of culture. The post-modernist identification of "culture" with colonialism and imperialism is a false diagnosis: marked by its reaction to Enlightenment universalism, the historico-ideological context within which the idea of culture took shape indicates the opposite. In turn, anxieties over the imminent end of human cultural variety are revealed to be groundless: globalisation and other capitalist phenomena, far from imposing a monotonous hegemony on the planet, have generated a historically unprecedented diversity of cultural forms and contents. 